\title{
Article \\ The systematic risk at the crisis - A multifractal non-uniform wavelet systematic risk estimation
}

\author{
Mounir Sarraj ${ }^{1,+}$ and Anouar Ben Mabrouk $2,3,4,+\infty$ \\ 1 Département de Méthodes Quantitatives, Faculté des Sciences Economiques et de Gestion de Sousse, \\ Universié de Sousse, Cité Riadh, 4023 Sousse, Tunisia; mounir.sarraj@fsegso.rnu.tn (M.S.) \\ 2 Laboratory of Algebra, Number Theory and Nonlinear Analysis, Department of Mathematics, Faculty of \\ Sciences, University of Monastir, Avenue of the Environment, Monastir 5019, Tunisia; \\ 3 Department of Mathematics, Faculty of Sciences, University of Tabuk, Tabuk 47512, Saudi Arabia \\ 4 Department of Mathematics, Higher Institute of Applied Mathematics and Computer Science, University \\ of Kairouan, Street of Assad Ibn Alfourat, Kairouan 3100, Tunisia; Anouar.benmabrouk@fsm.rnu.tn \\ (A.B.M.) \\ * Correspondence: anouar.benmabrouk@fsm.rnu.tn \\ + These authors contributed equally to this work.
}

\begin{abstract}
The Capital Asset Pricing Model is a widely applied model to describe risky markets and to deduce their systematic risk. Its estimation therefore remains an important task in econofinancial studies. Empirically, it focuses on the impact of return interval on the betas. Existing studies somehow turn around the same idea of measuring the value of the beta according to the uniform intervals of time during a fixed period. However, it is noticed easily, and especially the last decade that many factors such as socio-political, and econo-environmental ones have led to a perturbation in the time-line of the worldwide development, and especially in countries and regions having political changes. This led us to introduce a new idea of risk estimation taking into account the non-uniform changes in markets by introducing a non-uniform wavelet analysis. We aim to explain the econo-political situation of Arab spring countries, and the effect of the revolutions on the market beta. The main novelty is firstly the construction of a dynamic backwardforward model for missing data, and next the application of random non-uniform wavelets. The proposed procedure will be acted empirically on a sample corresponding to TUNINDEX stock as a representative index of the Tunisian market actively traded over the period January 14, 2016 to January 13, 2021. The chosen 5-years period is important as it constitutes the first 5-years-after the revolution and depends strongly on the socio-econo-political stability in the revolutionary countries.
\end{abstract}

Keywords: Wavelets; Non-uniform wavelets; CAPM; Wavelets CAPM; systematic (market) risk; scaling; Arab spring revolutions.

JEL Classification: G11; C02; C22.

\section{Introduction and motivations}

It is well known that economies are based to a large extent on the corresponding financial markets, local as well as external. Local markets explain or reflect the internal policies of governments and the internal laws that govern the movement of money locally such as local prices, internal laws of economics and finance, production, development, etc. The interaction with foreign markets explains and reflects first of all the effectiveness of foreign affairs policy, import-export movements, the quality of the export, ..., etc.

To control the situation of the market, controllers such as governments apply usually qualitative and quantitative measurements such as purses and or indices. This permits to econo-financial agents such as Financial markets to reconcile the antagonistic objectives of their clientele such as profitability, security and liquidity. 
To guarantee a non risky or at least less risky (secure) portfolios, with high level of profitability, investors has to make into consideration may factors, such as time, securities, risk, profitability, policies, ... etc, (See [1-8]).

Since these studies, the CAPM has became a basic model in financial studies, and permitted in many cases the description of the link some factors raised above. However, its empirical validity has been investigated after by works of [9]. Next, in the 1990's decade, the empirical studies have been growing up, raising in some cases the problem of time intervals in the use of the CAPM. Indeed, Fama-French stated in [10] that the classical way of annual time intervals may not induce good results, and thus raised the necessity of using adapted time intervals for the estimation of systematic risk beta, such as monthly and weekly data due to many causes such as the seasonal effect of returns, the non-synchronization of actions, etc (See [1,2,11-27]). However, many studies already taking into account the time factor in the CAPM validation have concluded that the estimations may lead to biased beta when using even monthly, weekly and more precisely short (uniform) periods (see [28-34]). Recall that short uniform periods may induce a great problem of frequency estimation and/or volatility/fluctuation control in the market. In this context, the authors in [35] and [36] stated that the lack of distinction between the time domain and the frequency may be, indeed, causes of the the limitations of conventional approaches. See also [37].

Due to these studies, a great interest to the time factor has been considered by researchers on the validity of the CAPM and the relationship between the systematic risk and the return of securities. This issue is still relevant in financial studies.

One of the recent tools involved in the econo-financial studies to understand and to include the time factor in the models is the so-called wavelet approach. Indeed, Wavelets form a mathematical tool that transforms time domain data into different frequency horizons. They represent the advantage of being localized in both the time and frequency domains. Wavelets since their appearance and especially their involvement in financial time series and economic models understanding showed their efficiency to offer sophisticated algorithms. They constituted attractive mathematical tools in the modeling of several complicated situations such as in economics and finance. Financial indices are usually volatility and highly fluctuated, which imposes the need to advanced mathematical tools for their study, such as wavelets which have shown ability to detect and/or localize fluctuations and volatility.

Related to the risk in markets, Marfatia developed a wavelet approach in [35] for the impact of risks in international stock markets by involving wavelet techniques into time-varying conditional volatility. The wavelet modeling permitted to conclude that co-movement of risks between the US market and European markets are more strong explained at lower frequencies, contrarily to regional markets versus the country, where the co-movement is much stronger at higher frequencies, See also [36].

Related to the CAPM, wavelet variants have been developed leading to the socalled wavelet CAPM (WCAPM) by analysing data at different time scales, making it possible to overcome the inadequacies of the classical analysis of the CAPM. For more backgrounds on wavelets and their applications the authors may refer to [38-45].

The present study lies in the whole scope of the integration and/or the study and evaluation of risks in stock markets according to time changes. Focus are made on the involvement of wavelet theory in estimating the systematic risk beta relative to crisis and precisely sharp socio-political movements.

A main aim in our present paper is to understand the nature of the relationship linking systematic risk and the return on equities for the Tunisian stock markets as a representative of the so-called Arab spring revolutions' countries. Recall that, compared to other countries in such a set, Tunisia is the most stabilized country that could pass the revolutionary period without a great instability us in some other countries where afterrevolution wars have been broken out between the regimes and opposite parts. Such situations have now influenced quasi all the world by inducing great movement of illegal 
immigration, refugees movements, appearance and spread of terrorist organizations, ..., etc.

The irregular movements have induced a perturbation in the time-line of the worldwide development, economy, finance, and especially in countries and regions having the socio-political changes. We aim precisely in the present work to introduce a new idea of risk estimation taking into account the non-uniform changes in markets by introducing a non-uniform wavelet analysis. We aim to explain the econo-political situation of Arab spring countries, and the effect of the revolutions on the market beta. The main novelty is firstly the construction of a dynamic backward-forward model for missing data, and next the application of random non-uniform wavelets. The proposed procedure will be acted empirically on a sample corresponding to TUNINDEX stock as a representative index of the Tunisian market actively traded over the period January 14, 2016 to January 13,2021 . The chosen 5 -years period is important as it constitutes the first 5 -years-after the revolution and depends strongly on the socio-econo-political stability in the revolutionary countries. The period of study is also characterized by the appearance of the corona pandemic spread in all the world. It is well known the influence of such pandemic on the economic situations on worldwide countries, especially the Arab spring ones. The crisis such as COVID-19 pandemic have also shown the weakness in worldwide countries relationships and supports to each other during severe moments. Until now, many countries classified as poor suffer from the severe situation of the pandemic without real and high support in view of vaccination availability. From an empirical point of view, the approach may also be a real foundation for effective financial decisions, which depend usually on the accuracy of the valuation of the securities, their evolution and their risks.

We recall in particular, that Tunisia has a strategic geographic position in the mid of the south Mediterranean sea, which allows it to be a central point in the inter-changing between the north and the south rivers, and thus plays a great role in the economic, social and political movements in this region of the world. Relatively to the present work, and especially to the period chosen for study, Tunisia has established a long-standing co-operation with the European council since 2011, just after the revolution, to develop many sectors such as human rights, democracy, combating violence, improving the functioning of justice, the fight against corruption, which were immediately reflected in the partnership with Tunisia especially in the period 2015-2021. These priorities have and/or will have surely a great effect on the stability of the country, and thus permits the investment and the development to be pursued. As a consequence, the different after-revolution governments have established many social, political, economic and financial projects that have a direct impact on the national market as well as interacted ones. This makes it of interest to study such market and understand its complexities.

Now, from a practical point of view, in the present case of study, the data collected, based on yahoo finance and the web site investing.com, unfortunately has many missing values, in different time positions such as the beginning, the mid, and the end of the period of investigation. Consequently, our work becomes a twofold study. In a first step, we developed a wavelet-based method to reconstruct missing data. It consists of backward-forward method, in which we applied for indices starting adequately a forward prediction of the missing values, and for indices with missing data at the beginning we have applied a backward prediction to reconstruct the first values of the data. The missing mid values are estimated as overages of the application of the two previous procedures. The method looks like the lifting from a multiresolution horizon to the previous and vice versa. level The complete set is by the next applied for CAPM and thus the comprehension of the market.

The rest of the present work is organized as follows. In section 3, a literature review on forecasting systematic risk is developed. Section 4 is devoted to the development of our methodology. We especially re-develop the wavelet analysis of time series briefly to apply it by the next for missing data reconstruction which in turns will be applied 
for completing the data basis used later. The mathematical formulation of the CAPM is provided by the next. Finally, this section is achieved by the development of the wavelet CAPM. Section 5 is subject of our empirical results and their discussions on the Tunisian TUNINDEX stock market. Section 6 is a conclusion. The findings in the present work may be good basis for understanding current and future situation and may be thus a basis for investors' decisions in such markets. We intend that our method will be adapted to non-uniform, multifractal, random and stochastic aspects in the market, and to explain the market situation at the crisis.

\section{The CAPM and the time factor review}

This section is concerned to the literature review of the original construction of the CAPM. This come back to the early 1950's decade in the works of Markowitz [6] on portfolio selection. Markovitz thought that the CAPM is mainly applied for solving the problem of portfolio's structure. This needs to an estimation of the demand function of assets to incorporate the quantified treatment of risk, which in turns leads to the investigation of the market's equilibrium. However, Markovitz framework did not take into account the time factor, which causes a strong limitation. Besides, Markovitz model [6] stated that the investor optimal choices are based on the expected return of investments and the risk of the portfolio. The model suggests to select stocks relative to statistical criteria such as the profitability.

The original version of the CAPM has been a governing measure or index to explain and interpret the behaviour of the market for a long period such as the estimation of the capital cost for companies, the evaluation of the performance of managed portfolios despite the problems confronted in its empirical evaluation, and which are related to many causes in the market such as the availability of data.

The CAPM in its original and/or modified versions is based indeed on many assumptions that should be taken into consideration, but which may not be satisfied simultaneously in all situations. These may be resumed into several points.

- mono-periodicity,

- market perfection aspect without taxes nor transaction costs,

- homogeneity in anticipations,

- unlimited short selling,

- $\quad$ loans and borrowing at the risk-free and limitless rate,

- $\quad$ strictly increasing and strictly concave Von-Neumann-Morgenstern utility functions,

- mean-variance preferences based on restrictions relating to the return or the utility function,

- investor aversion to risk,

- competition and market efficiency.

Next, in quietly a decade, the mathematical formulation has been put out by Sharpe who continued to exploit such a formalism and its efficiency in explaining the market movement and extended the CAPM to overcome some cases of limitations due to the last assumptions by proposing the so-called CAPM with non-homogeneous anticipations ([46-48]).

In a parallel time or direction, Lintner investigated the risk assets and the selection of stock portfolios, and the CAPM with taxes in [3,4]. Other extensions have been also proposed by $[33,49,50]$ such the CAPM with transaction costs and the CAPM in continuous time. In [51] however, the authors criticized the profitability of a stock as a criterion to confirm about the opportunity of the investment, and stated instead that it is not sufficient to do. The authors asserts that a good measure of the total risk of a portfolio may be the variance of its profitability.

Mathematically speaking the CAPM is a linear relationship between the expected return on the share or portfolio and the market premium where the linearity coefficient is often denoted $\beta$ and is known as systematic risk. It tests the mean-variance efficiency 
and involves the ranking of assets and portfolios against systematic risks by practitioners. It thus analyses the return and risk of an investment. In [4] and [8], the main idea of the CAPM turns around the estimation of the prices of transferable securities allowing supply and demand to be balanced and allowing a general equilibrium of the market. Sharpe proved effectively that for each asset $i$, the coefficient $\beta_{i}$ is the quotient of the covariance between the rate of return of asset $i$ and the rate of return of the portfolio by the square of market risk. Other factor may affect the CAPM such that diversification which is indeed strongly related to the behaviour of the expectation-variance of the portfolio. The contribution of each security to the expected profitability of the portfolio is in fact proportional to its expected profitability.

In the literature, despite the governance of the original versions of the CAPM for a long period in financial studies, many criticisms related to the portfolio and/or the market have been addressed for such versions. In [9] for example, an empirical criticism has been pointed out relative to the representative portfolio of the market. See also [52-54].

The main drawback of these versions may be resumed in the fact that the estimated betas are assumed to be stable relatively to the time scale and thus relative to the whole period of study. However, in the real aspect of the financial market, the time factor is always present although being hidden in the model. For example, the standard deviation of the market is always variable according the time.

For this reason, many researchers have focused on the inclusion of the time factor, at least in the empirical extensions of the CAPM relatively to the time variations of the beta or the risk premium, or sometimes both of them. Marfatia and collaborators, for example, showed in a series of works ([35,36,55-57]) that different estimators of the risk may be obtained according to the difference in the time interval of returns (see also $[28,32])$. Handa et al rejected in [29] the monthly periods for the estimation of the CAPM beta, and accepted instead the annual returns.

The concept of time becomes thus a crucial and indispensable factor for the validity of the CAPM, and still constitutes an essential and relevant issue. One of the challenging ideas that have been recently involved in the CAPM, and in the investigation of financial markets is due to wavelet theory. which permits essentially to show the presence of the time-scale division to overcome the shortcomings of the classical CAPM analysis. Our aim in the present work is to continue exploiting the validity of the CAPM by means of wavelet theory. The focuses are made on the Tunisian TUNINDEX stock market in a critical period known as the after-revolution state. We aim firstly to analyze the systematic risk and to point out its limitations taking into account the time factor. The second is to identify the relationship between equity returns and their systematic risks using the wavelet approach taking already the time factor into account.

In our knowledge, the application of wavelets for revolutions' transition periods, before and after needs more developments. The wavelet method however, has been applied for stable markets such as SP500 (USA), CAC40 (France), ISE (Istanbul) and GCC markets. [58] applied wavelets for the stock markets of the US, UK and Germany to estimate the best time scale for measuring systemic risk. The authors concluded that the relationship between risk and return is a multi-scale phenomenon. [59] analyzed the Santiago stock market in Chile using time-scaling methodology. [60,61] studied the French CAC40 index as market portfolio and the daily EURIBOR as the risk-free rate. The predictions of the CAPM are claimed to be more relevant in the short term than in the long term, which makes the French market different from those of the US, UK and Germany. [62] applied the wavelet multi-scaling method for the Istanbul Stock Exchange during the period from January 2003 to October 2007. It is shown that a positive relationship between risk and returns is most significant at the medium levels, concluding that the effect of market returns on an asset is stronger in this time horizon. In [39], the author developed a wavelet study for the largest GCC market Saudi Tadawul in order to understand such market on a critic period which post follows many important 
movements infusing directly and strongly on the market. In the next section, we will address the details of our mathematical methodology in exploiting wavelet theory differently from existing works in the analysis of the CAPM.

For more details, backgrounds, and applications of wavelet theory in finance, economics, management and generally actuarial sciences, the readers may refer for instance to [38-45,58], [59], [63-76].

\section{Wavelets for financial series processing}

\subsection{The wavelet processing classical view}

A wavelet may be defined simply as a short wave function oscillating as the cosine and sine waves, but with high frequency and small support. Such a behaviour is known as the localization in time-frequency, and/or time-space. As in Fourier analysis, to analyse signals such as financial time series, wavelet analysis also is based on a type of transform defined by means of a convolution of the analyzed signal with wavelets obtained from the same source function $\psi$ called the mother wavelet, a square-integrable function with enough vanishing moments (oscillating) with necessary zero mean. To analyse financial time series, the mother wavelet should satisfy the hypothesis

$$
\mathcal{A}_{\psi}=\int_{\mathbb{R}} \frac{|\widehat{\psi}(\xi)|^{2}}{|\xi|} d \xi<\infty,
$$

known as the admissibility condition (See [77-81]). These wavelets are obtained by translation, and dilation of the mother wavelet by means of a dilation factor $a>0$ (known as the scale), and a translation factor $b \in \mathbb{R}$ (known as the position) as

$$
\psi_{a, b}(x)=\frac{1}{\sqrt{a}} \psi\left(\frac{x-b}{a}\right) .
$$

Therefore, the continuous wavelet transform (CWT) of an analyzed function $F \in L^{2}(\mathbb{R})$ is

$$
C_{F}(a, b)=\int_{-\infty}^{+\infty} F(t) \psi_{a, b}(t) d t
$$

which depends as its form shows on the scale and the position parameters. This explains its nomination as the CWT of $F$ at the scale $a$ and the position $b$.

In the case of discrete signals such as the financial time series, this is of course evaluated by means of the discrete integrals or the discrete convolution. Indeed, it is proved in wavelet theory that a restrictive version of the CWT (called the discrete wavelet transform (DWT)) suffices to overcomes many cases such as the financial series. It is obtained by restricting the scale and the position factors to discrete grids. The most commonly known restriction is the dyadic grid $a=2^{-j}$, and $b=k 2^{-j}, j, k \in \mathbb{Z}$. The wavelet $\psi_{a, b}$ is therefore written as

$$
\psi_{j, k}(t)=2^{j / 2} \psi\left(2^{j} t-k\right) .
$$

The discrete wavelet transform (DWT) (called also the wavelet coefficient or detail coefficient at the level $j$, and the position $k$ ) is defined by

$$
d_{j, k}(S)=C_{F}\left(2^{-j}, k 2^{-j}\right) .
$$

In wavelet theory we know that the set $\left(\psi_{j, k}\right)_{j, k \in \mathbb{Z}}$ constitutes an orthonormal basis of $L^{2}(\mathbb{R})$, and consequently any element $F$ may be decomposed in a series

$$
F=\sum_{j, k} d_{j, k}(S) \psi_{j, k}
$$


known as the wavelet series of $F$, and guarentees a reconstruction formula of the original analyzed function $F$.

In the case of a discrete function $S$ such as the financial time series this formulation may be easily adapted, by means of a convolution product permitting to write the wavelet detail coefficients $d_{j, k}(S)$ as a cpnvolution product

$$
d_{j, k}(S)=\sum_{n} F(n) \psi_{j, k}(n)
$$

This decomposition of the series $S$ into an orthogonal-wise components series may be explained also and equivalently by means of a multiresolution framework by splitting it into two orthogonal parts,

$$
S=\sum_{j \leq J, k} d_{j, k}(S) \psi_{j, k}+\sum_{j>J, k} d_{j, k}(S) \psi_{j, k}
$$

relative to a fixed integer $J \in \mathbb{Z}$. If we denote for $j \in \mathbb{Z}, W_{j}=\operatorname{spann}\left(\psi_{j, k} ; k \in \mathbb{Z}\right)($ known as the detail spaces), and $V_{j}=\bigoplus_{l \leq j}^{\perp} W_{l}$ (known as the approximation spaces), we get in one hand an orthogonal decomposition $V_{j}=V_{j-1} \stackrel{\perp}{\bigoplus} W_{j-1}$. On the other hand, the part

$$
A_{J}(S)=\sum_{j \leq J, k} d_{j, k}(S) \psi_{j, k}
$$

(called the approximation of $F$ at the level $J_{0}$, which is also the projection of $F$ on $V_{J_{0}}$ ) belongs to $V_{J}$, and the part

$$
D_{j}(S)=\sum_{k} d_{j, k}(S) \psi_{j, k}
$$

(called the detail component of $F$ at the level $j$, which is also the projection of $F$ on $W_{j}$ ) belongs to the space $W_{j}$. In other words, the series $S$ is written as

$$
S=A_{J}(S)+D_{J+1}(S)+D_{J+2}(S)+\ldots
$$

It holds that the component $A_{J}(S)$ describes the global behavior, the trend, or the shape of $S$, and a second part reflects the higher frequency oscillations or the fine scale deviations of the series near its trend.

To compute or to evaluate these parts, we have not to compute necessary all the coefficients appearing in the decomposition. We instead serve of some filters and algorithms permitting to reduce the cost of the computation. Indeed, it holds in wavelet theory that there exists a special function $\varphi$ (known as the scaling function or the father wavelet) for which $V_{j}=\operatorname{spann}\left(\varphi_{j, k} ; k \in \mathbb{Z}\right)$, where the $\varphi_{j, k}$ 's are defined similarly to the $\psi_{j, k}$. Such function is related to the mother wavelet by means of the so-called 2-scale relation

$$
\varphi=\sum_{k \in \mathbb{Z}} h_{k} \varphi_{1, k}, \text { and } \psi=\sum_{k \in \mathbb{Z}} g_{k} \varphi_{1, k}
$$

where

$$
h_{k}=\int_{-\infty}^{+\infty} \varphi(t) \varphi_{1, k}(t) d t, \text { and } g_{k}=(-1)^{k} h_{1-k} .
$$

The approximation $A_{J}(S)$ will be therefore expressed by means of the basis of $V_{J}$ as

$$
A_{J}(S)=\sum_{k} a_{J, k}(S) \varphi_{J, k}
$$


where the coefficients $a_{j, k}$ (known as the approximation or scaling coefficients of $S$ ) are evaluated as the $d_{j, k}$ by replacing the function $\psi$ by $\varphi$. The relation (12) permits to compute the wavelet coefficients recxursively as

$$
\begin{aligned}
& a_{j, k}(S)=\sum_{l \in \mathbb{Z}} h_{l} a_{j+1, l+2 k}(S), \\
& d_{j, k}(S)=\sum_{l \in \mathbb{Z}} g_{l} a_{j+1, l+2 k}(S),
\end{aligned}
$$

and

$$
a_{j+1, k}(S)=\sum_{l} h_{l-2 k} a_{j, l}(S)+\sum_{l} g_{l-2 k} d_{j, l}(S) .
$$

This means that the wavelets permit to deduce the decomposition of the series $S$ at different levels from each other by means of the filters $H=\left(h_{k}\right)_{k}$ (discrete wavelet low-pass filter), and $G=\left(g_{k}\right)_{k}$ (discrete wavelet high-pass filter).

In practice, obviously, a restriction a maximal level is needed. For this we fix two integers $J>J_{0} \in \mathbb{Z}$ and consider the approximation

$$
S_{J}=A_{J_{0}}(S)+\sum_{J_{0}<j \leq J} D_{j}(S) .
$$

The lower index $J_{0}$ is in fact more flexible, does not have an important effect on the total decomposition and usually chosen to be 0 . The choice of $J$ is always critical, and is related to the eventual error estimates relative to the error applied to get the closeness of $S_{J}$ to the origin $S$. See [77-81] for more details.

\subsection{The non-uniform wavelet processing}

Non-uniform wavelets constitute an extension or improvement of wavelets by involving some modifications on the original way of use of wavelets. In the original wavelet analysis, we usually search for perfect representations of functions, time series, and generally analyzed objects by means of a set of uniformly-spaced samples. However, in nature, and practice, it may exists many cases of objects with non-uniformly-spaced samples such as structures sampled well-below the Nyquist rate. Indeed, the authors investigated in [82] a new approach called non-uniform wavelet sampling based on combining wavelet pre-processing with non-uniform sampling in order to alleviate the main issues of existing converter solutions, such as signal noise. A specialized variant of nonuniform wavelet band-pass sampling has been proposed by combining traditional band-pass sampling with nonuniform wavelet sampling. The method has been shown to be performant and efficient relative to the classical approaches.

In [83], a framework of non-uniform wavelets has been proposed for a special choice of Haar wavelet. Non-uniform Haar scaling and wavelet functions have been been introduced provided with a corresponding non-uniform multiresolution analysis and non-uniform wavelet transform and inverse transform. The approach has been tested for the case of bounded intervals, compression and reconstruction.

In [84], the dependence or the link between returns, betas and the return interval has been investigated. Based on the well-known Fama-french three factor model, the authors showed that both the mean returns and the betas are affected by the choice of time interval over which returns are measured. The authors proposed there the use of stochastic (thus, non-uniform) time intervals to describe more the situation of the market.

In the present work, we are concerned with this last approach, which will be applied as a suitable non-uniform wavelet sampling for the study of the CAPM. Other examples and methods to construct non-uniform wavelets and sampling may be found in [82]. To do this, we will recall here the construction of the non-uniform Haar wavelet due to [83]. 
Haar wavelet system and multiresolution is based on the Haar scaling function $\varphi=\chi_{[0,1[}$, and the mother wavelet $\psi=\chi_{[0,1 / 2[}-\chi_{[1 / 2,1[}$. The idea to construct a non-uniform scaling function, nun-uniform wavelet and a non-uniform corresponding multiresolution analysis adapted to time series starts by subdividing the time interval of the series into suitable subdivision. Assume without loss of the generality that the series is defined on an interval $I=[0, T]$ and let $\left\{\Delta_{m}\right\}_{m=0}^{M}$ be a partition of $I$, with $M \in \mathbb{N}$ given such that $\Delta_{m}=\left\{x_{k}^{(m)}\right\}_{k=0}^{2^{m}}$, where

$$
\left\{\begin{array}{l}
x_{0}^{(m)}=0<\cdots<x_{k}^{(m)}<\cdots<x_{2^{m}}^{(m)}=T \\
\text { and } \\
x_{k}^{(m-1)}=x_{2 k}^{(m)},\left(\text { this guarantees that } \Delta_{m} \text { is a refinement of } \Delta_{m-1}\right)
\end{array}\right.
$$

for all $m \in\{1,2, \ldots, M-1, M\}$, and $k \in\left\{0, \ldots, 2^{m-1}\right\}$. For each $m$, there will be a non-uniform scaling function $\varphi^{(m)}$ defined on each interval $x_{k}^{(m)}<\cdots<x_{k+1}^{(m)}$ by

$$
\varphi^{(m)}(x)=\varphi_{k}^{(m)}(x)=\varphi\left(\frac{x-x_{k}^{(m)}}{x_{k+1}^{(m)}-x_{k}^{(m)}}\right)=\chi_{\left[x_{k}^{(m)}, x_{k+1}^{(m)}\right.}\left[(x), x \in\left[x_{k}^{(m)}, x_{k+1}^{(m)}[\text {. }\right.\right.
$$

Similarly, the non-uniform wavelet $\psi^{(m)}$ will be defined as

$$
\begin{aligned}
\psi^{(m)}(x) & =\psi_{k}^{(m)}(x)=\psi_{\alpha_{k}^{(m)}}^{(m)}\left(\frac{x-x_{k}^{(m)}}{x_{k+1}^{(m)}-x_{k}^{(m)}}\right) \\
& =\alpha_{k}^{(m)} \chi_{\left[x_{2 k+1}^{(m+1)}, x_{2 k+2}^{(m+1)}[\right.}(x)-\left(1-\alpha_{k}^{(m)}\right) \chi_{\left[x_{2 k}^{(m+1)}, x_{2 k+1}^{(m+1)}[\right.}(x),
\end{aligned}
$$

where

$$
\alpha_{k}^{(m)}=\frac{x_{2 k+1}^{(m+1)}-x_{k}^{(m)}}{x_{k+1}^{(m)}-x_{k}^{(m)}}
$$

The non-uniform multiresolution analysis will be the sequence of spaces

$$
V_{m}=\operatorname{spann}\left\{\varphi_{k}^{(m)} ; k=0, \ldots, 2^{m}-1\right\},
$$

as approximation spaces, and

$$
W_{m}=\operatorname{spann}\left\{\psi_{k}^{(m)} ; k=0, \ldots, 2^{m}-1\right\},
$$

as detail spaces. In [83], it is proved that this construction leads as in the classical cases, to a 2-scale relation and some construction/reconstruction algorithms. More precisely, the following result is proved.

Proposition 1. ([83])

The functions $\varphi_{k}^{(m)}$ and $\psi_{k}^{(m)}$ satisfy the following relations.

$$
\begin{gathered}
\varphi_{k}^{(m-1)}=\varphi_{2 k}^{(m)}+\varphi_{2 k+1^{\prime}}^{(m)} \\
\psi_{k}^{(m-1)}=-\left(1-\alpha_{k}^{(m-1)}\right) \varphi_{2 k}^{(m)}+\alpha_{k}^{(m)} \varphi_{2 k+1}^{(m)} \\
\varphi_{2 k}^{(m)}=\alpha_{k}^{(m-1)} \varphi_{k}^{(m-1)}-\psi_{k}^{(m-1)}, \\
\varphi_{2 k+1}^{(m)}=\left(1-\alpha_{k}^{(m-1)}\right) \varphi_{k}^{(m-1)}+\psi_{k}^{(m-1)} .
\end{gathered}
$$


Let $f \in V_{m}$ be written as

$$
f=\sum_{k \in \mathbb{Z}} a_{k}^{(m)} \varphi_{k}^{(m)}=\sum_{k \in \mathbb{Z}} a_{k}^{(m-1)} \varphi_{k}^{(m-1)}+\sum_{k \in \mathbb{Z}} c_{k}^{(m-1)} \psi_{k}^{(m-1)} .
$$

We have the following filter rules for the reconstruction,

$$
\begin{gathered}
a_{k}^{(m-1)}=\left(1-\alpha_{k}^{(m-1)}\right) a_{2 k+1}^{(m)}+\alpha_{k}^{(m-1)} a_{2 k}^{(m)}, \\
c_{k}^{(m-1)}=a_{2 k+1}^{(m)}-a_{2 k}^{(m)},
\end{gathered}
$$

and the following for the decomposition,

$$
\begin{gathered}
a_{2 k}^{(m)}=a_{k}^{(m-1)}-\left(1-\alpha_{k}^{(m-1)}\right) c_{k}^{(m-1)}, \\
a_{2 k+1}^{(m)}=a_{k}^{(m-1)}+\alpha_{k}^{(m-1)} c_{k}^{(m-1)} .
\end{gathered}
$$

\section{Methodology}

Our aim as raised above is the development of a general version of the CAPM that takes into account two main factors such as the missing data and the time factor by applying wavelet time-frequency analysis. Our new idea consists firstly in applying a backward-forward method to reconstruct missing data, and next a non-uniform time scaling in the evaluation of the wavelet CAPM by means of a set of non uniformlytimed samples corresponding to the so-called non-uniform wavelets instead of classical wavelets.

\subsection{The original mathematical formulation of the CAPM}

The CAPM in its initial form is mathematically expressed by means of the equation

$$
R_{i, t}=\alpha_{i}+\beta_{i} R_{m, t}+u_{i, t}
$$

based on the return rate of an action $i$ at the period time $t$ denoted $R_{i, t}$, the return of the market measured by means of a general index at the same period of time $t$ and denoted $R_{m, t}$, the beta coefficient or the systematic risk which is a specific factor to each action $i$ that indicates the relation between the fluctuations of the return rate of the action $i$ and the fluctuations of the general index of the market. This is denoted here $\beta_{i}$. The factor $u_{i, t}$ is a random factor relative to the hidden facts of the return $R_{i, t}$ that are not explained by the market. It is generally an error term. Finally, the parameter $\alpha_{i}$ is a calibration factor for a null expectation of the error $u_{i, t}$.

According to the model (19), the CAPM splits the total variability of an action into two main parts. One part is relative to the market, and corresponds to the systematic risk. The second is related to the specific characteristics of the action, and reflects the variations of the specific prices of such action.

In the literature, due to the movements in the markets, the appearance of new crisis, many socio-polytical and economic movements in the world, the CAPM has been modified many times to be adapted to the situation studied. For example, in [8] the risk beta is evaluated as the ratio of the covariance of the assets and the market by the variance of the market during the whole period of study,

$$
\beta_{i}=\frac{\operatorname{Cov}\left(R_{i}, R_{m}\right)}{\operatorname{Var}\left(R_{m}\right)}=\frac{\sigma_{i m}}{\sigma_{m}^{2}}
$$

leading to an expectation based formulation

$$
E\left(R_{i}\right)=r_{f}+\beta_{i}\left(E\left(R_{m}\right)-r_{f}\right) .
$$


where $E\left(R_{i}\right)$ is the expected return of the action $i, E\left(R_{m}\right)$ is the expected return of the market, and $r_{f}$ is the so-called remuneration of the risk-free.

Another form of the CAPM depends on the number of investors in the market. Denote $K$ the total number of such investors, and assume that each investor $k=1,2, \ldots, K$ have to allocate a wealth $T_{k}$ in a number $M_{k}$ of actions. The risk beta is evaluated as the ratio the covariance $\sigma_{i k}$ between the return of action $i$ and the portfolio by the variance $\sigma_{k}^{2}$ of the optimal portfolio (relative the the $k$-th investor), $\beta_{i k}=\frac{\sigma_{i k}}{\sigma_{k}^{2}}$. The CAPM is written on the form

$$
E_{i}=r_{f}+\beta_{i k}\left(E_{k}-r_{f}\right),
$$

where $E_{i}$ is the expectation of the return of action $i$, and $E_{k}$ is the expectation of the return of the optimal portfolio detained by the $k$-th investor. See $[1,2,50]$.

Some extending variants of the CAPM may be also found in the literature such as the inflation-based CAPM, and taxation-based CAPM ([85]), CAPM depending on heterogeneity of anticipations ([62]).

In our present work, the model of the CAPM expressed by means equation (21), where we recall that $E\left(R_{i}\right)$ is the expected return due to the asset $i, r_{f}$ is the risk-free rate, $E\left(R_{m}\right)$ is the market portfolio expected return, and $\beta_{i}$ is the measure of risk for asset $i$ evaluated by means of equation (20).

Now, empirically, as in the literature, the risk or the coefficient $\beta_{i}$ will be evaluated by applying the usual ordinary least square method via a linear regression on the form

$$
R_{i t}-r_{f t}=\alpha_{i t}+\beta_{i}\left(R_{m t}-r_{f t}\right)+u_{i t}
$$

where the index $t$ is designated for the time, $u_{i t}$ is the error term while $\alpha_{i t}$ is a calibration or regulation constant. By means of the variance measure, this means that the variance of the asset $i$ is splitted into two parts such as

$$
\sigma_{i}^{2}=\beta_{i}^{2} \sigma_{m}^{2}+\sigma_{\varepsilon_{i}}^{2}
$$

The first part $\beta_{i}^{2} \sigma_{m}^{2}$ corresponds to the firm's systematic risk. while the second part $\sigma_{\varepsilon_{i}}^{2}$ corresponds to the firm's unsystematic risk.

\subsection{Backward-forward wavelet reconstruction of missing data}

The present section is concerned to the development of a wavelet approach for the well-known problem of missing and uncertain data confronted usually in financial time series. We aim to develop a prior procedure to complete the gaps of data used in the study. Indeed, in the present case of study, we noticed that the origin data bases such as web sites, although they are widely used, there is always and already a big lack of data. Usually the simple method to fill the gaps may be done by searching for different suppliers. This in turns may lead again to uncertain data, costs, and also loss of time. We thus thought about sophisticated methods to fill the gaps of data instead of applying non scientific methods.

Our procedure to be applied here is in fact a modified or a compilation of the one developed in $[39,41]$ to reconstruct missing data on short time intervals, differently from classical methods where in the majority of cases, the prediction is just applied to construct future values based usually on a long-time training interval from past values. In the present study, some cases of data has missing values in the beginning (the past) that have to be filled. Moreover, in some situations such as the target period applied here, some characteristics such as seasonality, periodicity and/or auto-regressive aspect could not be applied. This is obvious for many causes, such as the main characteristic of the period which is known as the spring Arab revolution period, and which in turns was followed by many important political, social, financial and economic movements not present in the past, and which the governments work hardly to overcome them. 
Let $S(t), t \in[0, T]$ be the financial time series. To be adequate with the notations of statistical series, we will write $\left(t_{i}, S_{i}\right), i=1,2, \ldots, N$, the financial series, and consider its wavelet decomposition at a level $J$, relative to a (father,mother) wavelet system $(\varphi, \psi)$,

$$
S^{J}=\sum_{k} a_{J_{0}, k} \varphi_{J_{0}, k}+\sum_{j=J_{0}+1}^{J} \sum_{k} d_{j, k} \psi_{j, k} .
$$

The missing values are classified into two classes.

- $\quad$ For a missing value $S_{k}, k=1,2, \ldots, N$, we compare the lengths of the known segments after and before this values. We next chose the one with greater length. Denote for example $L_{k}$ such greater length, and $I_{k}=\left\{i_{1}^{k}, i_{2}^{k}, \ldots, i_{L_{k}}^{k}\right\}$ the interval corresponding.

- $\quad$ Consider next the truncated time series $\widetilde{S}_{i}$ corresponding to $\left(t_{i}, S_{i}\right), i \in I_{k}$, and its wavelet decomposition as in (25).

- If $I_{k}$ is an after-interval to the missing value, we estimate the value $S\left(i_{1}^{k}-1\right)$ by

$$
\widehat{S_{i_{1}^{k}-1}}=\frac{\sum_{m=1}^{L_{k}} S_{i_{m}^{k}} K\left(\frac{t_{i_{m}^{k}}+t_{i_{1}^{k}-1}}{h}\right)}{\sum_{m=1}^{L_{k}} K\left(\frac{t_{i_{m}^{k}}+t_{i_{1}^{k}-1}}{h}\right)}
$$

- If $I_{k}$ is a before-interval to the missing value, we estimate the value $S\left(i_{L_{k}}^{k}+1\right)$ by

$$
\widehat{S_{i_{L_{k}}^{k}+1}}=\frac{\sum_{m=1}^{L_{k}} S_{i_{m}^{k}} K\left(\frac{t_{i_{m}^{k}}-t_{i_{L_{k}}^{k}+1}}{h}\right)}{\sum_{m=1}^{L_{k}} K\left(\frac{t_{i_{m}^{k}}-t_{i_{L_{k}}^{k}+1}}{h}\right)}
$$

where $K$ is a suitable prediction kernel, and $h$ is a suitable prediction window.

- Whenever the after and before intervals have the same length we take the mean value of the two predicted ones.

- It remains the case where many successive values in the series are missing. We thus consider the extremities of the missing segments as starting points to be predicted.

- Finally, each predicted value is added to the series, and the new series is reconsidered for the next step.

In the present work, a recursive procedure is applied as in [86], by acting the previous rules (26)-(27) on the approximation and the detail coefficients by considering

$$
\widehat{a_{j, L_{k}+1}}=\frac{\sum_{m=1}^{L_{k}} a_{j, m} K\left(\frac{m-\left(L_{k}+1\right)}{h}\right)}{\sum_{m=1}^{L_{k}} K\left(\frac{m-\left(L_{k}+1\right)}{h}\right)}, \text { and } \widehat{d_{j, L_{k}+1}}=\frac{\sum_{m=1}^{L_{k}} d_{j, m} K\left(\frac{m-\left(L_{k}+1\right)}{h}\right)}{\sum_{m=1}^{L_{k}} K\left(\frac{m-\left(L_{k}+1\right)}{h}\right)},
$$

and similarly

$$
\widehat{a}_{j, i_{1}^{k}-1}=\frac{\sum_{m=1}^{L_{k}} a_{j, m} K\left(\frac{m+\left(i_{1}^{k}-1\right)}{h}\right)}{\sum_{m=1}^{L_{k}} K\left(\frac{m+\left(i_{1}^{k}-1\right)}{h}\right)} \text {, and } \widehat{d}_{j, i_{1}^{k}-1}=\frac{\sum_{m=1}^{L_{k}} d_{j, m} K\left(\frac{m+\left(i_{1}^{k}-1\right)}{h}\right)}{\sum_{m=1}^{L_{k}} K\left(\frac{m+\left(i_{1}^{k}-1\right)}{h}\right)} .
$$


This means that to forecast the value of the series, the procedure is transformed to the prediction of its wavelet/scaling components. We thus obtained a dynamic recursive scheme consisting in applying firstly a partial estimator at short horizons to all the observations to yield firstly the predicted values. These values are included as new observations to predict the next. We then follow the same steps until reaching the desired horizon. For backgrounds, more details, and other applications of analog methods to the present one, the readers may refer to $[39,74,86,87]$.

\subsection{The wavelet CAPM processing}

The idea of the wavelet estimation of the CAPM goes back essentially to the works of $[44,67]$, and [59]. In the first references, the authors introduced the general framework of wavelet analysis of time series, and the eventual applications in finance and economics. Next, Fernandez [59] has focused essentially on the CAPM and its improvement by means of wavelets by adopting the time scale factor in the empirical study. The investigations and applications of the wavelet methods in the CAPM have been next growing up (see $[23,34,35,39,44,45,57-63,67,68,70,75,76])$.

The wavelet CAPM consists in decomposing the variance of the financial series issued from the whole market index, and the actions in the market (or the portfolio) into sub-variances corresponding to the decomposition levels $j$ (called the $j$-level variance or the variance at the scale $j$ ). More precisely, denote as in the previous sections $S(t)$, $t \in[0, T]$ a financial time series, and $\sigma_{S}^{2}$ its variance. Denote also $\sigma_{S}^{2}(j)$ the variance of the projection $A_{j}(S)$ on the $j$-level approximation space $V_{j}$ due to the multiresolution. The variance $\sigma_{S}^{2}$ is splitted as

$$
\sigma_{S}^{2}=\sum_{j} \sigma_{S}^{2}(j)
$$

This leads to the analysis of the sub-variances relative to the different horizons $j$ instead of the total one, which facilitates the analysis and the interpretation. The $j$-level variance $\sigma_{S}^{2}(j)$ is evaluated as in $[39,40,59,62]$ as

$$
\widehat{\sigma}_{X}^{2}(j)=\frac{1}{2^{j}\left(N_{j}-L_{j}\right)} \sum_{k=L_{j}-1}^{N_{j}-1} d_{j, k^{\prime}}^{2}
$$

$L$ is the length of the wavelet filter, $N_{j}=\left[N / 2^{j}\right]$ is the number of wavelet coefficients involved in the $j$-level approximation of the series, and $L_{j}=\left[2^{-j}(L-2)\left(2^{j}-1\right)\right]$ stands for the number of boundary wavelet coefficients at the level $j$. The same principle will be also applied for the $j$-level covariance between a couple $(X, Y)$ of financial series

$$
\widehat{\sigma}_{X Y}^{2}(j)=\frac{1}{2^{j}\left(N_{j}-L_{j}\right)} \sum_{k=L_{j}-1}^{N_{j}-1} d_{j, k}^{X} d_{j, k}^{Y} .
$$

To apply our wavelet method to the estimation of the CAPM, the series considered will be replaced by the returns due to the market and those due to the actions. The coefficient beta estimated in (20) will be replaced by the so-called wavelet beta at the level $j$ as

$$
\widehat{\beta}_{i}(j)=\frac{\widehat{\sigma}_{R_{i} R_{m}}(j)}{\widehat{\sigma}_{R_{m}}^{2}(j)}
$$

where $\widehat{\sigma}_{R_{i} R_{m}}(j)$ is the wavelet covariance of the component $i$ of the portfolio with the market at the scale $j$ estimated by (30), with $X$ being replaced by the $j$-level approximation/details of the return $R_{i}$, and $Y$ is replaced by the $j$-level approximation/details of the return $R_{m}$, and finally, $\widehat{\sigma}_{R_{m}}^{2}(j)$ is the $j$-level wavelet variance due to the $j$-level approximation/details of the return $R_{m}$ of the market. 
The final step allowing to explain the explanatory power of the market returns on the portfolio returns, is concerned to the estimation of the determination coefficient $R_{i}^{2}(j)$ for each return time scale as follows

$$
R_{i}^{2}(j)=\beta_{i}(j)^{2} \frac{\sigma_{R_{m}}^{2}(j)}{\sigma_{R_{i}}^{2}(j)} .
$$

The main procedure in the present work is to serve of the non-uniform wavelet analysis to estimate the risk beta, compare with existing methods (based on uniform estimations), and deduce eventually the power of the new process. We will thus denote for the rest of the paper $\beta^{c}$ to designate the classical beta estimated without use of wavelets, $\beta^{u}$ to designate the classical wavelet beta, and $\beta^{n u}$ to designate the non-uniform wavelets introduced here. Similarly, we will adopt the same notations (upper-scripts) for the $R^{2}$ determination coefficient.

\section{The multifractality of the market}

Financial time series are always characterized by the stylized facts. The nature or the aspect of the distribution tail has always to be noticed. This may be done via the kurtosis measure which permits to confirm if the series is leptokurtic or not.

Financial time series have also high frequency components, explained always by the volatility clustering. This behavior is always explained by the presence of many hidden factors and/or aspects such as the random or stochastic behavior of markets.

To understand these problems in the market, the researchers have included the so-called scaling law invariance in the study of the volatility or the market in general. Many tools have been thus investigated for the aim of understanding aspects of non stationary, auto-regression, filtering, support vector machine models and prediction, neural networks models and predicting.

However, it seems that wavelets are the last tool involved, and are the most efficient compared to past tools. In financial series, indeed, there are underlying the fluctuations causal information cascades from increasing (large) to decreasing (small) time scales called self-similarity law or generally scaling law. Such facts may be easily visualized with the wavelet representation.

To confirm the presence of the fractal/multifractal behaviour of the market, such as the self similarity, a multifractal test should be done consisting in evaluating the multifractal spectrum of the index.

An original way to evaluate such a spectrum starts by evaluating the increments of the index. For a series $S$, these are defined as

$$
\Delta S_{i}=S\left(t_{i+1}\right)-S\left(t_{i}\right)
$$

for a suitable subdivision of the time interval. Next, we compute an associated partition function by means of the $q$-increments as

$$
Z(q)=\sum_{i=0}^{N_{v}}\left|\Delta x_{i}\right|^{q} .
$$

The scaling law $\tau(q)$ is obtained by regressing the logarithm $\log Z(q)$ of the partition function $Z(q)$ against the step time $\log v$ in the sense that

$$
Z(q) \approx v^{\tau(q)}
$$

The scaling function $\tau(q)$ yields next the multifractal spectrum by means of the Legendre transform

$$
d(\alpha)=\inf _{q}(\alpha q-\tau(q))
$$


In general, for mono-fractal series, we get a linear scaling function. In the case where the series is volatile (highly volatile), the scaling function should be a concave curve. So, the multifractal test will consist in visualizing the scaling law function $\tau$ or equivalently the multifractal spectrum $d(\alpha)$.

Another way to explore the volatile behavior of the market is to conduct the socalled detrended fluctuation analysis (DFA) in its original form or its recent wavelet extension. The DFA of the series $S_{i}=X_{t_{i}}, i=1,2, \ldots, N$ statrs by computing its integrated form

$$
I S_{t}=\sum_{i=1}^{t}\left(S_{i}-\bar{S}\right),
$$

where $\bar{S}$ is the mean value of the series $X_{t}$. Let next $n \in \mathbb{N}$ be fixed and $I_{k}, k=1, \ldots, n$ be a subdivision of the time interval $I_{N}$. For all $k$, the least squares fit (denmoted $I S_{t}^{k}$ ) of the series $I S_{t}$ is associated $I S_{t}^{k}$. An overage fluctuation function is next introduced as

$$
A F_{S_{t}}(n)=\sqrt{\frac{1}{N} \sum_{i=1}^{N}\left(I S_{i}-I S_{i}^{n}\right)^{2}} .
$$

The DFA consists in evaluating the power-law dependence of the function $A F_{S_{t}}(n)$ on $n$. When $A F_{S_{t}}(n) \sim n^{\alpha}$, the series is self fluctuating with scaling exponent $\alpha$.

The DFA is next extended or improved by the so-called multifractal detrended fluctuation analysis (MDFA), which is based essentially on two parameters,

- the Hurst-Hölder exponent which permits to estimated the local regularity of the series and consequently leads to the fluctuations inside it.

- the multifractal spectrum of the series which allows to conclude about its possible multifractality of it. form

The main idea improved by the MDFA is by considering general increments of the

$$
\Delta_{v}^{m} S(t)=\sum_{j=0}^{m}(-1)^{m-j}\left(\begin{array}{c}
m \\
j
\end{array}\right) S(t+j v),
$$

for $m \in \mathbb{N}$. Such an increment should be next estimated as

$$
\Delta_{v}^{m} S(t) \sim v^{H_{S}(t)}
$$

The exponent $H_{S}(t)$ plays the role of the so-called Hurst-Holder exponent.

However, to avoid the difficult use of the functional spaces mathematical definition of such exponents, the MDFA has been re-developed using the wavelet tools. Indeed, in the wavelet MDFA (WMDFA), the partition function is defined as

$$
Z_{j}(q)=2^{-j} \sum_{k}\left|d_{j, k}\right|^{p}
$$

at a level of decomposition $j$. the $d_{j, k}$ are the well known wavelet coefficients (detail) or sometimes the wavelet leaders (applied in the last variant of WMDFA). To test the multifractal structure and compute next the multifractal spectrum we seek a function $\tau(q)$ that reflects the scaling law of $Z_{j}(q)$ as

$$
Z_{j}(q) \sim 2^{-j \tau(q)}
$$

Backgrounds and details on multifractal analysis of financial (time) series, DFA, MDFA and WMDFA may be found in [38,62,77,78,88-97]. 


\section{Empirical results and discussions}

In this part, we will examine the influence of non-uniform time scale law on the understanding of the systematic risk beta relative to the Tunisian index TUNINDEX due to the Tunisian market as a representative of the so-called spring Arab countries. The influence of the political and social movements and instabilities on the economic situation and the future of the market will be investigated. In the literature on the CAPM, it is somehow confirmed that a linear dependence between action's returns and their systematic risks, and the risk of the market return exists. However, the dependence on the time scale is always hidden, and not explained explicitly in the mathematical model. Therefore, empirical investigations remain necessary to check such a dependence and influence. We thus focus in the present work on testing the hypotheses stating that

- The time scale law explains the stability/instability of the risk beta.

We propose in the empirical section to test a wavelet methodology of beta estimation on daily returns for TUNINDEX collected on the period of January 14, 2016 to January 13,2021 resulting of a sample size $N=1253$. We focused on a portfolio composed of 73 actions as listed in Table 1 with corresponding sectors. According to the Tunisian stock market web site, the first Tunisian market index was launched in September 30th 1990 under the name of BVMT index. TUNINDEX index and sector indices were created in December 31st 1997 and December 31, 2005 respectively. Theses indices aim to provide managers, analysts and savers with a measure of portfolios performance and stock market activities as a whole. Upon the decision of the expert committee, since January 02, 2009, BVMT index is no longer disseminated and the method of calculation of the TUNINDEX index and the sector indexes are changed. The TUNINDEX index and the sector indexes are no longer weighted by the total market capitalization but by the free float adjusted market capitalization. This method of calculation, already used for other major indices around the world, ensures greater coherence between the real nature of companies on the market and how it is expressed in the indices. (see http://www.bvmt.com.tn/en-gb/content/documentation). In fact during 2008-2013 a slightly different composition has been approved, but with no essential and great difference with the present one. It is based on the sector indices listed as Automobiles and parts, Banks, Construction, Consumer Goods, Industries, Raw Materials, Consumer Services, Financial Services, and Financial Companies. However, such a subdivision did not focus on the Energy sector for example, which is an important one in the econofinancial market in Tunisia as Oil and Phosphate for example are main energy exportation products. Therefore, an independent consideration of this sector is of great interest. Healthcare also is an active, and very important sector. Recall that, Tunisia was one of the rare countries that reached zero Corovavirus case at the first waves of the COVID-19. Tunisia has been also participated in fighting COVID-19 in many European countries such as Italy and Germany by medical groups. However, the last period, the country has confronted with a severe wave of COVID-19. The majority of analyzers explained this fact by the wide corruption in the last governments, especially the last one. Besides, the $\mathrm{n}$ on experienced governments after the revolution are strong cause of some failures. The sector of Technology did not appear also in the 2008-2013 composition, despite its importance. Recall here that a big number of industrial technological companies have already branches installed in Tunisia, due to the qualified, and also sheep labor as well as the short distance to Europe. The sector of Transportation needs also to be considered because of its basic role in the daily life of the people. It also serves to the transportation of import-export goods and materials such as Oil and Phosphate, and agricultural crops such as olive oil, dates, etc. 
Table 1: Tunindex Companies and Sectors.

\begin{tabular}{|c|c|c|}
\hline Sector & Company Name & Abbreviation \\
\hline \multirow{6}{*}{ Basic Materials } & ALKIMIA chemical company & ALKM \\
\hline & Carthage Cement & $\mathrm{CC}$ \\
\hline & Les Industries Chimiques du Fluor & ICF \\
\hline & One Tech Holding & $\mathrm{OTH}$ \\
\hline & Papier et Carton & STPAP \\
\hline & Societe Tunisienne de Verreries & STVR \\
\hline \multirow{8}{*}{ Capital Goods } & Les Ateliers Mecaniques du Sahel & AMS \\
\hline & Manufacture De Panneaux Bois Du Sud & MPBS \\
\hline & Les Ciments de Bizerte & SCB \\
\hline & Servicom & SERVI \\
\hline & Essoukna & SOKNA \\
\hline & Société Moderne de Céramique & SOMOC \\
\hline & Société Tunisienne d'Email & SOTEM \\
\hline & Société Tunisie Profilé Aluminium & TPR \\
\hline \multirow{16}{*}{ Consumer } & Accumulateur Tunisien Assad SA designs & ASSAD \\
\hline & Cerealis & CREAL \\
\hline & Délice Holding & DH \\
\hline & Euro-Cycles & ECYCL \\
\hline & Societe Generale Industrielle de Filtration & GIF \\
\hline & Hannibal Lease & HANL \\
\hline & Land'Or & LNDOR \\
\hline & Electrostar & LSTR \\
\hline & New Body Line & NBL \\
\hline & Office Plast & PLAST \\
\hline & Poulina Group Holding & POULA \\
\hline & Société d'Articles Hygiéniques & SAH \\
\hline & Atelier du Meuble Interieurs & SAMAA \\
\hline & Société Frigorifique et Brasserie de Tunis & SFBT \\
\hline & Société de Production Avicole de Teboulba & SOPAT \\
\hline & Universal Auto Distributors Holding & UADH \\
\hline \multirow{2}{*}{ Energy } & Air liquid & $\mathrm{AL}$ \\
\hline & Transport des Hydrocarbures par Pipelines & STPIL \\
\hline \multirow{3}{*}{ Healthcare } & ADWYA company & ADWYA \\
\hline & Pharmaceutiques de Tunisie & SIPHA \\
\hline & nité de Fabrication des Médicaments & UMED \\
\hline \multirow{4}{*}{ Technology } & Advanced e-technologies & AETEC \\
\hline & Appareillage et Matériels Electriques & SIAM \\
\hline & Entreprises de Télécommunications & SOTE \\
\hline & Telnet Holding & TLNET \\
\hline Transportation & Société Tunisienne de l'Air & TAIR \\
\hline
\end{tabular}




\begin{tabular}{|c|c|c|}
\hline \multirow{17}{*}{ Financial } & Amen Bank & $\mathrm{AB}$ \\
\hline & Arab Tunisian bank & ATB \\
\hline & Banque De L'Habitat & $\mathrm{BH}$ \\
\hline & BH Assurance & BHASS \\
\hline & Banque Internationale Arabe Tunisie & BIAT \\
\hline & Banque Nationale Agricole & BNA \\
\hline & Banque Attijari De Tunisie & BS \\
\hline & Banque De Tunisie & BT \\
\hline & Banque De Tunisie Et Des Emirats & BTEI \\
\hline & Placement et Developpement Industriel et Touristique & SPDI \\
\hline & Société Tunisienne d'Assurances et de Réassurances & STAR \\
\hline & Societe Tunisienne De Banque (STB) & STB \\
\hline & Tuninvest SICAR & TINV \\
\hline & Société Tunisienne de Réassurance & TRE \\
\hline & Union Bancaire pour le Commerce et L'Industrie & UBCI \\
\hline & Union Internationale de Banques & UIB \\
\hline & Wifack International Bank and leasing & WIFAK \\
\hline \multirow{17}{*}{ Services } & Automobile Réseau Tunisien et services Renault & ARTES \\
\hline & Arab Tunisian lease & ATL \\
\hline & BH Modern Leasing & BHL \\
\hline & Cellcom & CELL \\
\hline & Compagnie Internationale De Leasing & CIL \\
\hline & City Cars & CITY \\
\hline & Hannibal Lease & HANL \\
\hline & Société Tunisienne des Marchés de Gros & MGR \\
\hline & Monoprix & MNP \\
\hline & Ennakl Automobiles & NAKL \\
\hline & Société Immobilière et de Participations & SIMP \\
\hline & Société Immobilière Tunisio Saoudienne & SITS \\
\hline & Societe Magasin General & SMG \\
\hline & Tawasol Group Holding & TGH \\
\hline & Attijari Leasing & TJL \\
\hline & Tunisie Leasing \& Factoring & TLS \\
\hline & Société HEXABYTE (internet) & XABYT \\
\hline
\end{tabular}

The choice of this market is motivated by the fact that Tunisia is a representative country of the so-called Arab spring, as target period of study which concerns the first 5-years-after the revolution and depends strongly on the socio-econo-political stability in the revolutionary countries. In the end of such period, the situation of the country has been affected as the rest of the world by the appearance of the pandemic COVID-19 which has a severe influence on the economic situation in all the world, especially the Arab spring countries where the political situation remained unstable also. Besides, and although many factors influenced the economic development in Tunisia, the strategic geographic position of the country in the mid of the south Mediterranean sea, allows it to be a central point in the inter-changing between the north and the south rivers, and thus plays a great role in the economic, social and political movements in this region of the world. Thus, a long-standing co-operation has been established with the European council since 2011, just after the revolution, to develop many sectors such as human rights, democracy, combating violence, improving the functioning of justice, the fight against corruption, which were immediately reflected in the partnership with Tunisia especially in the period 2015-2021. These priorities will have surely a great effect on the stability of the country, and thus permit the investment and the development to be pursued. It is also worth to notice that compared to other Arab spring countries, Tunisia is the most stabilized country that could pass the revolutionary period without a great instability as in some others where after-revolution wars have been broken out between 
the regimes and opposite parts. Such situations have now influenced quasi all the world by inducing great movement of illegal immigration, refugees movements, appearance and spread of terrorist organizations, ..., etc.

Now, the starting step consists in acting a wavelet (uniform or non-uniform) method to reconstruct missing data. On the total basis we recorded a total number of 206 missing values dispersed on the whole market, on different time dates (daily) as in Table 2. A complete and adjusted basis on the period of study is thus obtained and applied by the next.

Table 2: Missing data.

\begin{tabular}{l|c}
\hline Stock & Number of missing values \\
\hline ALKM & 15 \\
\hline AST & Omitted \\
\hline BL & Omitted \\
\hline BTEI & 03 \\
\hline CREAL & 25 \\
\hline HANL & 12 \\
\hline MIP & Omitted \\
\hline PLAST & 35 \\
\hline PLTU & Omitted \\
\hline SAMAA & 17 \\
\hline SIPHA & 5 \\
\hline SMD & Omitted \\
\hline SOTEM & 53 \\
\hline TVAL & Omitted \\
\hline UMED & 23 \\
\hline WIFAK & 18 \\
\hline Total & 206 Missing values \\
\hline
\end{tabular}

We propose to study the relationship between excess return on each individual stock and the time scales of market portfolio using (23). The daily return of each stock is estimated as a log-price difference

$$
R_{i t}=\log P_{i, t}-\log P_{i, t-1},
$$

where $P_{i, t}$ is the price of asset $i$ at day $t$. The market return $R_{m t}$ is similarly evaluated as a log-difference

$$
R_{m t}=\log I_{t}-\log I_{t-1},
$$

where $I_{t}$ is the index value at day $t$.

Table 3 below shows the descriptive statistics of the market. The statistics correspond precisely to the return excess for each company relatively to the risk-free. 
Table 3: Descriptive statistics of excess returns.

\begin{tabular}{|c|c|c|c|c|c|c|}
\hline Stocks & Mean & Maximum & Minimum & Std. & Skewness & Kurtosis \\
\hline Tunindex & 0.0002 & -0.0419 & 0.0268 & 0.0048 & -1.4085 & 15.2260 \\
\hline$A B$ & 0.0087 & -2.4888 & 13.2143 & 0.4131 & 25.0862 & 842.1409 \\
\hline ADWYA & -0.0000 & -0.0678 & 0.0985 & 0.0168 & 0.5349 & 5.3468 \\
\hline ATEC & -0.0019 & -0.2136 & 0.1727 & 0.0277 & -0.4266 & 8.7224 \\
\hline $\mathrm{AL}$ & -0.0010 & -0.1050 & 0.0879 & 0.0187 & -0.3908 & 7.0118 \\
\hline ALKM & 0.0004 & -0.3394 & 0.2179 & 0.0373 & -1.4224 & 19.6617 \\
\hline AMS & -0.0014 & -0.2447 & 0.1620 & 0.0283 & 0.2387 & 10.3742 \\
\hline ARTES & -0.0003 & -0.0776 & 0.0581 & 0.0124 & -0.3018 & 7.7441 \\
\hline ASSAD & -0.0001 & -0.1389 & 0.1390 & 0.0173 & 0.3309 & 9.9634 \\
\hline ATB & -0.0004 & -0.0859 & 0.0705 & 0.0163 & 0.0910 & 6.0719 \\
\hline ATL & -0.0004 & -0.1178 & 0.0635 & 0.0157 & -0.2162 & 7.8302 \\
\hline $\mathrm{BH}$ & -0.0001 & -0.0613 & 0.0592 & 0.0166 & 0.3649 & 4.0558 \\
\hline BHASS & 0.0005 & -0.1676 & 0.1313 & 0.0235 & -0.3755 & 7.8264 \\
\hline BHL & -0.0013 & -0.2333 & 0.1204 & 0.0236 & -0.5241 & 11.7126 \\
\hline BIAT & 0.0002 & -0.0628 & 0.0591 & 0.0119 & -0.0987 & 7.1844 \\
\hline BNA & -0.0002 & -0.0945 & 0.1008 & 0.0149 & 0.5917 & 7.9965 \\
\hline BS & -0.0000 & -0.0638 & 0.0586 & 0.0131 & -0.4141 & 7.6677 \\
\hline BT & -0.0002 & -0.2234 & 0.0812 & 0.0119 & -5.0655 & 107.1594 \\
\hline BTEI & -0.0010 & -0.1022 & 0.1313 & 0.0217 & -0.0025 & 6.8876 \\
\hline $\mathrm{CC}$ & 0.0002 & -0.4079 & 0.1244 & 0.0253 & -2.9116 & 57.6041 \\
\hline CELL & -0.0004 & -0.1468 & 0.1004 & 0.0242 & 0.0561 & 5.1432 \\
\hline CIL & 0.0001 & -0.0929 & 0.0574 & 0.0152 & -0.6240 & 7.5173 \\
\hline CITY & -0.0005 & -0.2813 & 0.0548 & 0.0155 & -4.9836 & 89.8893 \\
\hline CREAL & 0.0002 & -0.0886 & 0.0843 & 0.0222 & 0.0205 & 3.6709 \\
\hline $\mathrm{DH}$ & -0.0000 & -0.0640 & 0.0575 & 0.0141 & 0.0287 & 4.2832 \\
\hline ECYCL & 0.0000 & -0.0762 & 0.0876 & 0.0179 & 0.2912 & 5.2231 \\
\hline GIF & -0.0007 & -0.0712 & 0.2624 & 0.0240 & 2.0608 & 18.9931 \\
\hline HANL & -0.0009 & -0.2944 & 0.0788 & 0.0184 & -3.7005 & 57.9889 \\
\hline ICF & 0.0003 & -0.1473 & 0.1967 & 0.0266 & 0.3366 & 8.1322 \\
\hline LNDOR & 0.0004 & -0.0754 & 0.1015 & 0.0206 & 0.2629 & 4.3643 \\
\hline LSTR & -0.0011 & -0.0953 & 0.2537 & 0.0305 & 1.0498 & 8.5629 \\
\hline MGR & 0.0003 & -0.0954 & 0.0591 & 0.0157 & -0.0687 & 5.4146 \\
\hline MNP & -0.0006 & -0.0609 & 0.0585 & 0.0162 & 0.1608 & 3.8115 \\
\hline MPBS & -0.0004 & -0.1181 & 0.0598 & 0.0198 & -0.0302 & 4.6772 \\
\hline NAKL & 0.0001 & -0.1130 & 0.0411 & 0.0101 & -1.7371 & 23.5821 \\
\hline NBL & -0.0006 & -0.0987 & 0.0582 & 0.0159 & -0.3225 & 6.2855 \\
\hline $\mathrm{OTH}$ & 0.0005 & -0.0533 & 0.0575 & 0.0125 & 0.4109 & 5.1508 \\
\hline PLAST & -0.0005 & -0.2926 & 0.2551 & 0.0368 & -2.3356 & 22.3834 \\
\hline POULA & 0.0006 & -0.0600 & 0.0733 & 0.0143 & 0.4850 & 6.1390 \\
\hline
\end{tabular}




\begin{tabular}{lcccccc}
\hline SAH & 0.0003 & -0.0834 & 0.0570 & 0.0130 & -0.2102 & 6.8012 \\
SAMAA & -0.0002 & -0.1863 & 0.5857 & 0.0248 & 10.2429 & 252.4786 \\
SCB & -0.0010 & -0.1699 & 0.0994 & 0.0223 & -0.4036 & 8.3289 \\
SERVI & -0.0012 & -0.6222 & 0.4215 & 0.0382 & -2.2380 & 70.8611 \\
SFBT & -0.0000 & -0.2233 & 0.0581 & 0.0147 & -6.5972 & 99.4471 \\
SIAM & 0.0004 & -0.0734 & 0.0591 & 0.0162 & 0.3084 & 4.6604 \\
SIMP & -0.0005 & -0.0917 & 0.0884 & 0.0178 & -0.0846 & 4.7251 \\
SIPHA & -0.0009 & -0.2283 & 0.1644 & 0.0344 & -0.8407 & 8.3417 \\
SITS & -0.0001 & -0.1738 & 0.1101 & 0.0206 & -0.4421 & 11.5821 \\
SMG & -0.0004 & -0.1064 & 0.0872 & 0.0201 & -0.1493 & 5.1333 \\
SOKNA & -0.0007 & -0.0854 & 0.0580 & 0.0187 & -0.2385 & 4.1779 \\
SOMOC & -0.0006 & -0.0588 & 0.1325 & 0.0186 & 0.7649 & 6.1544 \\
SOPAT & -0.0005 & -0.0762 & 0.1495 & 0.0254 & 0.7514 & 4.9379 \\
SOTE & 0.0010 & -0.0935 & 0.1459 & 0.0249 & 0.7980 & 5.6197 \\
SOTEM & 0.0007 & -0.2538 & 0.1178 & 0.0266 & -1.2298 & 16.6829 \\
SPDI & 0.0001 & -0.0963 & 0.0864 & 0.0167 & -0.2026 & 6.8780 \\
STAR & -0.0002 & -0.1068 & 0.0631 & 0.0176 & -0.0117 & 5.0213 \\
STB & -0.0004 & -0.0785 & 0.0709 & 0.0178 & 0.2621 & 4.2858 \\
STPAP & 0.0001 & -0.1058 & 0.0587 & 0.0167 & -0.0425 & 5.9996 \\
STPIL & 0.0003 & -0.0975 & 0.0593 & 0.0168 & -0.0744 & 5.3405 \\
STVR & 0.0005 & -0.2045 & 0.0819 & 0.0168 & -0.9566 & 21.3257 \\
TAIR & -0.0002 & -0.0592 & 0.1586 & 0.0202 & 1.0954 & 7.7621 \\
TGH & 0.0003 & -0.0690 & 0.1710 & 0.0239 & 0.8023 & 6.9059 \\
TINV & 0.0004 & -0.1261 & 0.2003 & 0.0236 & 0.1690 & 9.3758 \\
TJL & -0.0008 & -0.1799 & 0.0591 & 0.0190 & -0.6743 & 10.1483 \\
TLNET & 0.0007 & -0.0920 & 0.0591 & 0.0171 & 0.3615 & 4.9269 \\
TLS & -0.0006 & -0.0596 & 0.0590 & 0.0172 & 0.1369 & 3.7408 \\
TPR & 0.0001 & -0.1193 & 0.0580 & 0.0140 & -0.4542 & 9.6766 \\
TRE & -0.0001 & -0.0739 & 0.0541 & 0.0132 & -0.1659 & 4.8217 \\
UADH & -0.0010 & -0.1045 & 0.1493 & 0.0254 & 0.7522 & 6.1941 \\
UBCI & -0.0005 & -0.2169 & 0.0965 & 0.0221 & -0.8370 & 12.1977 \\
UIB & 0.0000 & -0.0627 & 0.0590 & 0.0119 & -0.0748 & 6.8758 \\
UMED & -0.0000 & -0.0596 & 0.1255 & 0.0143 & 0.8344 & 8.8368 \\
WIFAK & -0.0006 & -0.9776 & 0.1110 & 0.0314 & -3.9557 & 746.9421 \\
XABYT & -0.0002 & -0.0872 & 0.0654 & 0.0187 & -0.2181 & 4.2306 \\
\hline & & & & & & \\
& & & & &
\end{tabular}

In the present case, an approximately zero median value is obtained. The flatness and distortion features of all stocks' returns are different from each other. Moreover, the Jarque-Bera test leads to $J B=1$ which rejected the null hypothesis at the $5 \%$ significance level, and 0 otherwise.

Notice from Table 3 that as in the majority of studies of financial markets, return excess of actions relatively to the risk-free as well as the return excess of the market relatively to its risk-free have always low skewness and high kurtosis.

Our analysis acts by projecting equation (23) relatively to time scales to test the effect of time on the systematic risk beta. This will be conducted by splitting the market returns into crystals or horizons relative to different time scales instead of using the classical periods such as weeks, moths, years.

The coefficients of the linear regressions will be estimated by the usual ordinary least square (OLS) estimates of the returns $\left(R_{i t}-r_{f}\right)^{j}$ on the one of the market $\left(R_{m t}-r_{f}\right)^{j}$ for each level $j$. This leads to a $j$-level mathematical formulation as

$$
\left(R_{i}-r_{f}\right)^{j}=\alpha_{i}^{j}+\beta_{i}^{j}\left(R_{m}-r_{f}\right)^{j}+\varepsilon_{i}^{j}=\alpha_{i}^{j}+\alpha_{i} D_{m}^{j}+\varepsilon_{i}^{j} .
$$

The correspondence scale and dynamic days applied here are resumed in Table 4. 
Table 4: Time scales.

\begin{tabular}{|c|c|c|}
\hline The time scale law & \multicolumn{2}{|c|}{ Number of dynamic days } \\
\hline \multirow{6}{*}{ 2-scale law classical method } & $\mathrm{J}=1$ & 2-4 dynamic days \\
\hline & $\mathrm{J}=2$ & 4-8 dynamic days \\
\hline & $\mathrm{J}=3$ & 8-16 dynamic days \\
\hline & $\mathrm{J}=4$ & 16-32 dynamic days \\
\hline & $\mathrm{J}=5$ & 32-64 dynamic days \\
\hline & $\mathrm{J}=6$ & 64-132 dynamic days \\
\hline \multirow{6}{*}{ 2-scale law uniform wavelets } & $\mathrm{J}=1$ & 2-4 dynamic days \\
\hline & $\mathrm{J}=2$ & 4-8 dynamic days \\
\hline & $\mathrm{J}=3$ & 8-16 dynamic days \\
\hline & $\mathrm{J}=4$ & 16-32 dynamic days \\
\hline & $\mathrm{J}=5$ & 32-64 dynamic days \\
\hline & $\mathrm{J}=6$ & 64-132 dynamic days \\
\hline \multirow{8}{*}{ Scale law for non-uniform wavelets } & $\mathrm{J}=1$ & $a_{1}-a_{2}$ dynamic days \\
\hline & $\mathrm{J}=2$ & $a_{2}-a_{3}$ dynamic days \\
\hline & $\mathrm{J}=3$ & $a_{3}-a_{4}$ dynamic days \\
\hline & $\mathrm{J}=4$ & $a_{4}-a_{5}$ dynamic days \\
\hline & $\mathrm{J}=5$ & $a_{5}-a_{6}$ dynamic days \\
\hline & $\mathrm{J}=6$ & $a_{6}-a_{7}$ dynamic days \\
\hline & $\ldots$ & $\ldots$ \\
\hline & $J=J_{\max }$ & $a_{J_{\max }}-a_{J_{\max }+1}$ dynamic days \\
\hline
\end{tabular}

$\left(a_{j}\right)_{j}$ is an integer-valued random sequence.

$J_{\max }$ is chosen in such a way that we cover approximately one year.

\subsection{The original CAPM processing}

The first step is concerned with the estimation of the different regressions of the return excess of actions relatively to the one of the market at different scales $j=1,2,3,4,5,6$ obtained by the OLS estimates methods due to the classical method based on the dyadic scales. These estimates are resumed in Table 5. 
Table 5: 2-scale law estimations of the return excess of actions on the market.

\begin{tabular}{|c|c|c|c|c|c|c|}
\hline STOCKS & Scale 1 & Scale 2 & Scale 3 & Scale 4 & Scale 5 & Scale 6 \\
\hline $\mathrm{AB}$ & -0.0002 & 0591 & -0.2180 & -0.3776 & 17.8485 & 2997 \\
\hline ADWY & -0.4076 & 2126 & 4743 & 0.2611 & 1.3677 & 1445 \\
\hline ATEC & & & & & & \\
\hline & & & & & & \\
\hline LKM & & & & & & 014 \\
\hline AMS & & 879 & 509 & & 006 & 9689 \\
\hline סיתו & & 509 & 865 & & 0.2132 & 3064 \\
\hline SSA & 9.6228 & 5458 & & -0.2662 & -0.2275 & 1833 \\
\hline TB & 0 & & & & & 468 \\
\hline$\Gamma \mathrm{L}$ & & & & & & 506 \\
\hline & & & & & & 4528 \\
\hline & & & -0.2609 & 31 & & -0.7261 \\
\hline U & & & & & & -0.9149 \\
\hline & & & & & & 7195 \\
\hline & & & & & & 922 \\
\hline & & & & & & 46 \\
\hline & & & & & & 21 \\
\hline & & & & & & 826 \\
\hline & & & & & & -0.7147 \\
\hline ELL & & & & & & -0.1628 \\
\hline & & & & & & \\
\hline & & & & & & 514 \\
\hline $\operatorname{RE}$ & & & & & & 224 \\
\hline & & & & & & 322 \\
\hline ECY & & & & & & 599 \\
\hline & & & & & & 3006 \\
\hline & & & & & & \\
\hline & & & & & & \\
\hline & & & & & 28 & 988 \\
\hline & & & & & & 696 \\
\hline & & & & & & -0.0730 \\
\hline & & & & & & -0.1613 \\
\hline & & & & & & \\
\hline & & & & & & \\
\hline & & & & & & \\
\hline & 0 & & & & & 13 \\
\hline & & & & & & 2959 \\
\hline oU & & -0.1 & -0.9960 & & -0.4406 & -0.0554 \\
\hline $\mathrm{AH}$ & -6.0135 & 3.2193 & 1.0731 & 0.5983 & 0.1785 & 0.9718 \\
\hline
\end{tabular}




\begin{tabular}{lcccccc}
\hline SAMAA & -6.8998 & 0.5338 & 1.0301 & 0.1694 & -0.7055 & 0.6076 \\
SCB & 4.1182 & 0.9101 & 0.3385 & -0.0799 & -0.6495 & 0.6318 \\
SERVI & -6.0288 & -1.7968 & -0.4037 & -1.2213 & -0.7486 & 1.0757 \\
SFBT & -0.0969 & -0.9255 & 2.1951 & 0.8171 & 0.1873 & 0.7301 \\
SIAM & 13.4455 & -2.0938 & 0.6366 & 1.6688 & 0.9618 & -0.1210 \\
SIMP & 1.5868 & 0.1124 & 0.1382 & 0.7009 & -0.7430 & 0.6222 \\
SIPHA & 1.7590 & 0.8249 & 0.6905 & -1.3421 & 0.8054 & 1.0517 \\
SITS & 1.0800 & 0.3311 & -0.5158 & 0.2688 & -0.2104 & -0.1411 \\
SMG & 0.1202 & 0.9981 & -0.7714 & -0.3344 & 0.4702 & -0.0715 \\
SOKNA & 1.8296 & 0.9958 & -0.3290 & 1.0725 & 1.1269 & -0.0022 \\
SOMOC & -4.2680 & 0.5659 & 0.4614 & 0.6776 & 0.1037 & -0.0181 \\
SOPAT & 3.4854 & -1.3874 & 1.3892 & 0.7178 & 0.1555 & 0.7017 \\
SOTE & -2.0371 & -2.2244 & -0.2732 & -1.8874 & -0.1659 & -0.1844 \\
SOTEM & 6.7572 & -3.7027 & 1.3099 & -1.6350 & -1.0877 & 0.5220 \\
SPDI & 9.7634 & 0.3961 & 0.4404 & -0.4555 & 0.0582 & 0.1018 \\
STAR & -0.7808 & -0.9420 & 0.8378 & -0.6899 & -0.4044 & -0.626 \\
7 STB & -1.7339 & -3.3515 & 1.4811 & 0.7048 & 0.1236 & -0.3066 \\
STPAP & 5.2770 & 1.4540 & -0.1801 & 0.6719 & 0.3612 & 0.0973 \\
STPIL & 4.7181 & 2.5081 & 0.9031 & -0.4841 & -0.6429 & 0.1618 \\
STVR & 0.2440 & -4.1733 & 0.2800 & 0.1239 & 0.6635 & -0.1412 \\
TAIR & -8.7601 & 0.8458 & 0.7183 & 2.0956 & -0.4845 & 1.0164 \\
TGH & 1.8449 & 0.4060 & 1.4901 & 1.2457 & -0.1457 & 0.3129 \\
TINV & 5.2113 & -2.5005 & 0.6575 & -0.2680 & -1.7215 & 0.5694 \\
TJL & 0.6007 & -0.6622 & -0.8262 & -0.3960 & 0.9857 & -0.4978 \\
TLNET & 0.1318 & -0.5631 & 0.6544 & -0.2373 & 0.2614 & 0.1005 \\
TLS & -3.1588 & -1.1106 & -0.1840 & 0.5625 & -0.1896 & 0.0433 \\
TPR & 3.5238 & 1.8559 & 0.0309 & 0.8883 & 0.2713 & 0.5553 \\
TRE & -2.7765 & -4.1528 & -0.4250 & -0.3026 & 0.1116 & -0.0639 \\
UADH & -3.6072 & 0.2348 & -0.0796 & -1.2127 & 0.6951 & -0.8228 \\
UBCI & 9.5095 & -1.9248 & 1.1071 & -2.5089 & 0.1628 & -0.8903 \\
UIB & 3.0589 & 0.2199 & -0.5420 & 0.0428 & 0.1087 & -0.0029 \\
UMED & 0.8953 & 0.0313 & 0.0958 & -0.0257 & 0.4525 & 0.0611 \\
WIFAK & -15.6149 & -0.4211 & -0.1457 & -5.4381 & 0.0236 & 0.1471 \\
XABYT & 2.4190 & 2.8599 & 0.3539 & 0.1379 & 0.4281 & -0.3605 \\
\hline & & & & & &
\end{tabular}

It is noticeable from Table 5 some quite but perturbed linearity between multi-scale return and systematic risk. Some linear relations are almost positive, some others are moderately positive. But, no universal law of positivity is dominating for the whole market. A great number of actions are negatively related to the market index. The global view could not permit to conclude a strong interpretation of the evolution of the market. The looking at the individual results indicates a perturbation to conclude if the relationship becomes stronger at the lower, medium or higher scales. The only conclusion that may be deduced is the existence of the linear relationship, although weak, and some times opposite from horizon to another. The perturbation may be of course a cause of the non-resistance of the market according to time indicator. It may be also due to the lack of many hidden factors that are not involved in the mathematical model such as policy actions, local economic policy, etc. Besides, the perturbation if it is not re-studied and denounced by other methods, means that some crisis is always present in the market explained by an opposite variation of the actions and the market. Mathematically and empirically speaking, Table 5 shows that no strong or confirmed law may be expected simultaneously for all the contribution of the $D_{m}^{i}$ relative to all components of the market based on the time scale. To confirm or denounce, or to understand more the findings in Table 5 , the corresponding determination coefficient $R^{2}$ is computed and presented in Table 6. 
Table 6: The 2-scale law determination coefficient $R^{2}$ relative to Table 5 .

\begin{tabular}{|c|c|c|c|c|c|c|}
\hline & \multicolumn{6}{|c|}{$R^{2}$ for each scale } \\
\hline STOCKS & Scale 1 & Scale 2 & Scale 3 & Scale 4 & Scale 5 & Scale 6 \\
\hline $\mathrm{AB}$ & 0.7003 & 0.2840 & 0.0395 & 0.0210 & 0.0021 & 0.0015 \\
\hline ADWYA & 0.0332 & 0.0625 & 0.0423 & 0.1978 & 0.0000 & 0.0013 \\
\hline ATEC & 0.6264 & 0.0070 & 0.0840 & 0.1962 & 0.0407 & 0.0429 \\
\hline AL & 0.2246 & 0.0805 & 0.0065 & 0.0133 & 0.0076 & 0.0017 \\
\hline ALKM & 0.1500 & 0.1414 & 0.0178 & 0.1542 & 0.0269 & 0.0020 \\
\hline AMS & 0.0000 & 0.0671 & 0.0774 & 0.0008 & 0.1178 & 0.0793 \\
\hline ARTES & 0.9693 & 0.0025 & 0.1212 & 0.0014 & 0.0037 & 0.0062 \\
\hline ASSAD & 0.9724 & 0.0822 & 0.2100 & 0.0438 & 0.0000 & 0.0033 \\
\hline ATB & $\mathrm{NaN}$ & 0.4003 & 0.0001 & 0.1929 & 0.0006 & 0.0016 \\
\hline ATL & 0.6609 & 0.0795 & 0.0072 & 0.0236 & 0.0056 & 0.0004 \\
\hline BH & 0.3103 & 0.3304 & 0.0062 & 0.1436 & 0.0488 & 0.0128 \\
\hline BHASS & 0.3768 & 0.9656 & 0.0061 & 0.0111 & 0.0145 & 0.0676 \\
\hline BHL & 0.9482 & 0.2947 & 0.2033 & 0.0106 & 0.0019 & 0.0408 \\
\hline BIAT & 0.8996 & 0.6675 & 0.2500 & 0.2339 & 0.0940 & 0.0921 \\
\hline BNA & 0.2540 & 0.0058 & 0.3824 & 0.3391 & 0.0092 & 0.0042 \\
\hline BS & 0.0176 & 0.0122 & 0.0071 & 0.2007 & 0.0042 & 0.0139 \\
\hline BT & 0.8582 & 0.2393 & 0.0026 & 0.0288 & 0.0191 & 0.0108 \\
\hline BTEI & 0.9388 & 0.8321 & 0.0122 & 0.0069 & 0.0004 & 0.0005 \\
\hline CC & 0.5648 & 0.0913 & 0.0003 & 0.0057 & 0.0035 & 0.0163 \\
\hline CELL & 0.1990 & 0.4494 & 0.0608 & 0.0928 & 0.0010 & 0.0016 \\
\hline CIL & 0.9085 & 0.0018 & 0.0024 & 0.0160 & 0.0140 & 0.0026 \\
\hline CITY & 0.9757 & 0.5729 & 0.0519 & 0.0055 & 0.0180 & 0.0118 \\
\hline CREAL & 0.0287 & 0.1457 & 0.0151 & 0.0507 & 0.0030 & 0.0051 \\
\hline DH & 0.6257 & 0.0103 & 0.0036 & 0.0231 & 0.0132 & 0.0750 \\
\hline ECYCL & 0.0565 & 0.0663 & 0.1028 & 0.1182 & 0.0365 & 0.0290 \\
\hline GIF & 0.4342 & 0.6332 & 0.1233 & 0.0643 & 0.0200 & 0.0383 \\
\hline HANL & 0.2507 & 0.1381 & 0.0151 & 0.0491 & 0.0100 & 0.0051 \\
\hline ICF & 0.0679 & 0.0120 & 0.0334 & 0.1624 & 0.0003 & 0.0014 \\
\hline LNDOR & 0.2902 & 0.0334 & 0.0204 & 0.0526 & 0.0041 & 0.0350 \\
\hline LSTR & 0.7423 & 0.3440 & 0.0107 & 0.0021 & 0.0374 & 0.0966 \\
\hline MGR & 0.9956 & 0.2100 & 0.0494 & 0.0009 & 0.0082 & 0.0005 \\
\hline MNP & 0.9207 & 0.0073 & 0.1081 & 0.0147 & 0.0002 & 0.0039 \\
\hline MPBS & 0.9969 & 0.8156 & 0.0041 & 0.0871 & 0.0200 & 0.0287 \\
\hline NAKL & 0.9816 & 0.0552 & 0.0240 & 0.0078 & 0.0563 & 0.0829 \\
\hline NBL & 0.4828 & 0.4368 & 0.1332 & 0.0125 & 0.0421 & 0.0811 \\
\hline OTH & $\mathrm{NaN}$ & 0.0013 & 0.0024 & 0.0164 & 0.0058 & 0.0044 \\
\hline PLAST & 0.9946 & 0.5496 & 0.1802 & 0.0251 & 0.0023 & 0.0003 \\
\hline POULA & 0.0029 & 0.0769 & 0.1340 & 0.1441 & 0.0003 & 0.0003 \\
\hline SAH & 0.5062 & 0.8546 & 0.3050 & 0.0283 & 0.0539 & 0.0828 \\
\hline
\end{tabular}




\begin{tabular}{lllllll}
\hline SAMAA & 0.9495 & 0.0548 & 0.1719 & 0.0093 & 0.0050 & 0.0322 \\
SCB & 0.9999 & 0.0932 & 0.0713 & 0.0071 & 0.0437 & 0.0697 \\
SERVI & 0.8756 & 0.2142 & 0.0209 & 0.0276 & 0.0113 & 0.0031 \\
SFBT & 0.0031 & 0.4723 & 0.2860 & 0.3348 & 0.0663 & 0.0401 \\
SIAM & 0.9225 & 0.3322 & 0.0441 & 0.3514 & 0.0117 & 0.0006 \\
SIMP & 0.2038 & 0.0335 & 0.0021 & 0.0317 & 0.0058 & 0.0351 \\
SIPHA & 0.2039 & 0.0501 & 0.0297 & 0.2947 & 0.0882 & 0.0483 \\
SITS & 0.2993 & 0.2304 & 0.0385 & 0.0000 & 0.0055 & 0.0023 \\
SMG & 0.0068 & 0.5108 & 0.1011 & 0.0003 & 0.0006 & 0.0002 \\
SOKNA & 0.2085 & 0.3592 & 0.0116 & 0.0462 & 0.0214 & 0.0000 \\
SOMOC & 0.6960 & 0.3516 & 0.0491 & 0.0834 & 0.0001 & 0.0000 \\
SOPAT & 0.2278 & 0.0524 & 0.1416 & 0.0127 & 0.0012 & 0.0096 \\
SOTE & 0.1083 & 0.5722 & 0.0059 & 0.0192 & 0.0002 & 0.0005 \\
SOTEM & 0.5056 & 0.7964 & 0.0658 & 0.1461 & 0.0323 & 0.0060 \\
SPDI & 0.2929 & 0.0341 & 0.0744 & 0.3858 & 0.0270 & 0.0026 \\
STAR & 0.1902 & 0.0925 & 0.2389 & 0.0229 & 0.0191 & 0.0382 \\
STB & 0.0697 & 0.6182 & 0.2045 & 0.0395 & 0.0134 & 0.0093 \\
STPAP & 0.3598 & 0.1938 & 0.0035 & 0.0466 & 0.0031 & 0.0005 \\
STPIL & 0.9240 & 0.7733 & 0.1090 & 0.0090 & 0.0066 & 0.0025 \\
STVR & 0.0011 & 0.7426 & 0.0049 & 0.0735 & 0.0005 & 0.0011 \\
TAIR & 0.9952 & 0.0837 & 0.0559 & 0.0063 & 0.0000 & 0.0372 \\
TGH & 0.2038 & 0.0822 & 0.0823 & 0.0255 & 0.0017 & 0.0063 \\
TINV & 0.6976 & 0.5765 & 0.0325 & 0.0183 & 0.0009 & 0.0075 \\
TJL & 0.0023 & 0.3057 & 0.0914 & 0.0036 & 0.0162 & 0.0152 \\
TLNET & 0.0031 & 0.0883 & 0.0174 & 0.0496 & 0.0047 & 0.0009 \\
TLS & 0.3366 & 0.1541 & 0.0374 & 0.1243 & 0.0153 & 0.0002 \\
TPR & 0.4286 & 0.5080 & 0.0002 & 0.1443 & 0.0017 & 0.0169 \\
TRE & 0.2593 & 0.4923 & 0.0542 & 0.0553 & 0.0002 & 0.0007 \\
UADH & 0.5193 & 0.0291 & 0.0191 & 0.0383 & 0.0017 & 0.0702 \\
UBCI & 0.1316 & 0.4816 & 0.1277 & 0.0016 & 0.0085 & 0.0324 \\
UIB & 0.2104 & 0.0324 & 0.0777 & 0.0182 & 0.0000 & 0.0000 \\
UMED & 0.9651 & 0.0108 & 0.0036 & 0.0248 & 0.0011 & 0.0002 \\
WIFAK & 0.9907 & 0.0567 & 0.0634 & 0.0364 & 0.0001 & 0.0101 \\
XABYT & 0.0432 & 0.5415 & 0.0127 & 0.0261 & 0.0490 & 0.0071 \\
\hline
\end{tabular}

It is easily noticeable from Table 6 some quite decreasing aspect of the coefficient $R^{2}$ according to the time scale. However, it already presented some perturbation also in such a monotony, which is indeed not conserved along all time horizons, especially in the fourth (16-32 dynamic days) and the fifth (32-64 dynamic days) horizons. Globally, at low horizons the market is going down. Economically speaking this is a bad information for small companies and/or short investments.

The next step permits to explain more and visually the situation of the market via the eventual link between the actions' returns and the one of the market. Figure 1 below illustrates the 2-scale time law recomposed crystal of the excess return on the stock versus the corresponding crystal on the market portfolio. 

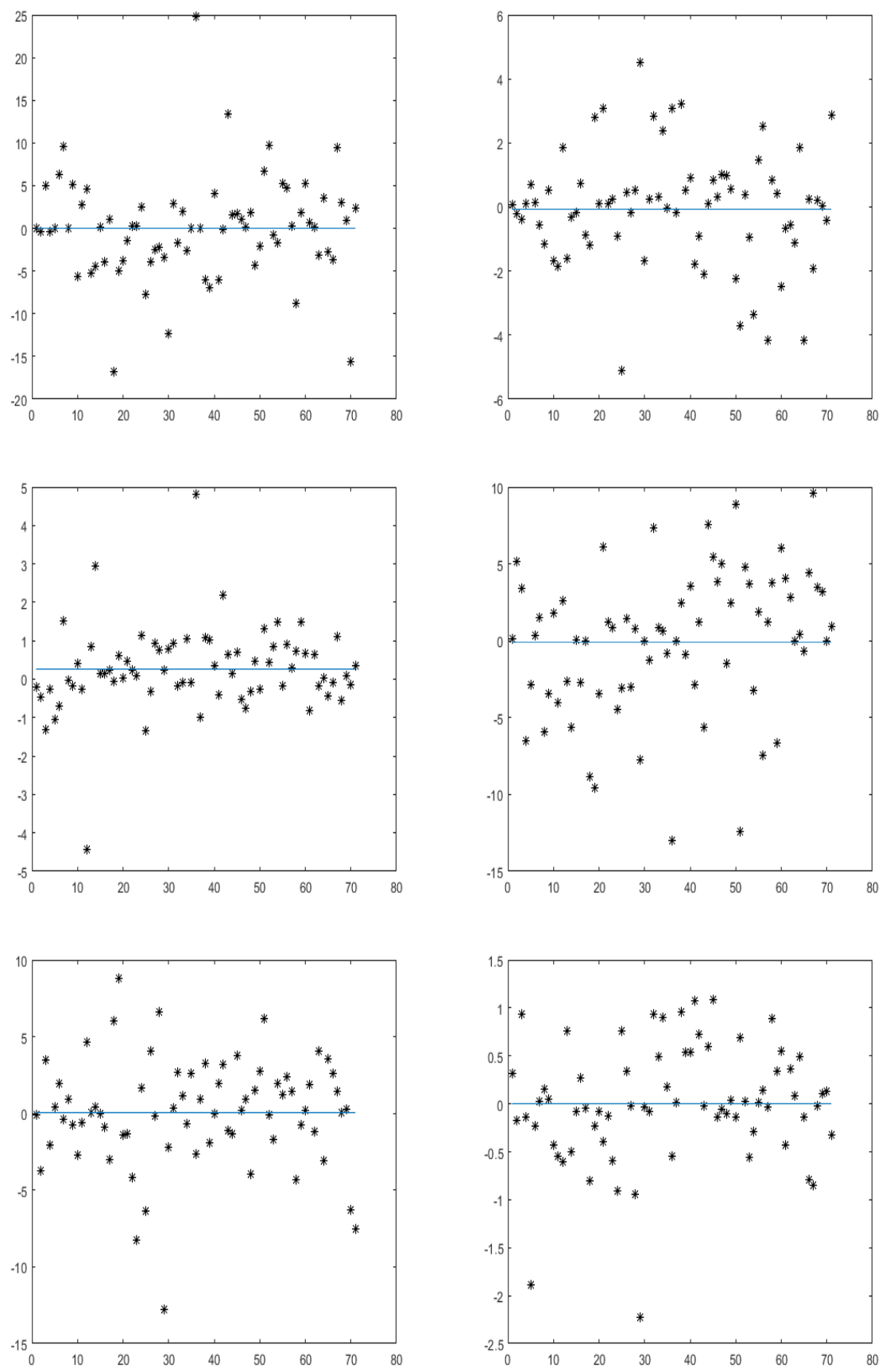

Figure 1. Excess market return (horizontal axis) versus excess return of the action (vertical axis) for different time scales with the 2-scale law.

In Figure 1 the daily stock returns versus corresponding stock beta at different time scales are plotted. By inspecting such a representation, it is noticeable clearly that the linearity is confirmed between the average betas of stocks and average returns at every scale (no matter being strong positive or not). This reinforces the usual finding about the CAPM as linear relationship. However, such figure shows clearly the suffering of the market from a serious crisis. Indeed, the market did not conserve the same resistant linearity along the whole period for the majority of actions. At law horizons (scale 1) the linearity is clear, and becomes perturbed at the scale 2, to return acceptable at scale 3 , perturbed at scale 4 and quietly acceptable at scales 5 and 6 . This evidence supports 
the proposition to act more sophisticated tools to zoom out the market and to discover the hidden behavior. Besides, the figure confirms our conclusion previously about the market being non encouraging for small companies and short investments. The next section essays to overcome these problems by adopting wavelet tools.

\subsection{The (wavelet) multifractal processing}

In financial case, for example, the studies have shown that the tail distribution is not leptokurtic but in the contrary, it has a kurtosis exceeding the normal case. In the present case, a kurtosis value over-crossing the normal one is detected in quasi all the statistical series. Moreover, the skewness induces for many times some negative values which means that the data are spread out more to the left relatively to the mean of the series than to the right.

To show how clearly the high volatile aspect of the market, a wavelet analysis is conducted in order to appear eventual fluctuations. Such analysis yielded the following illustrations in Figure 2 relative to the wavelet decomposition at the level 6 by means of a uniform wavelet decomposition 2.
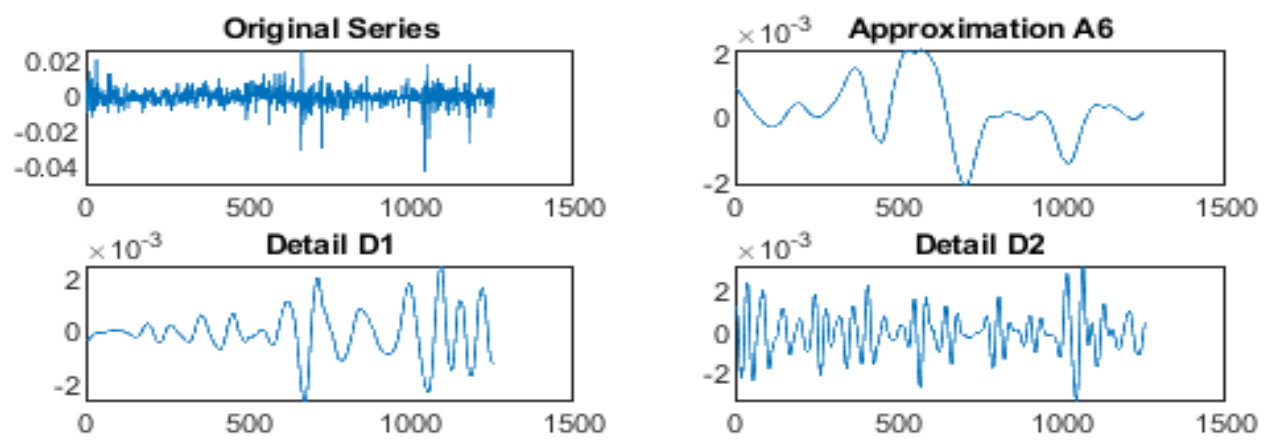

Detail D3
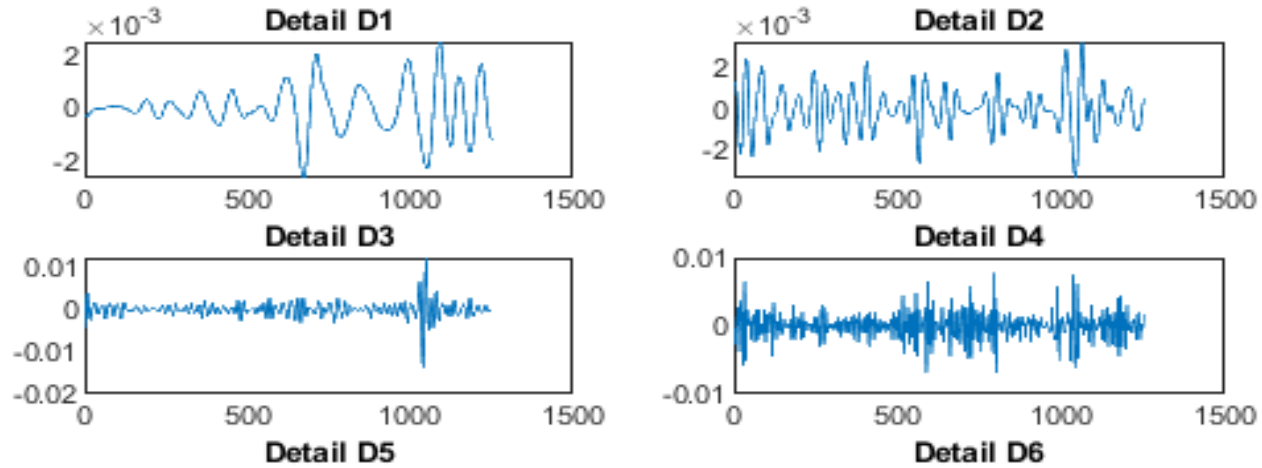

Detail D4
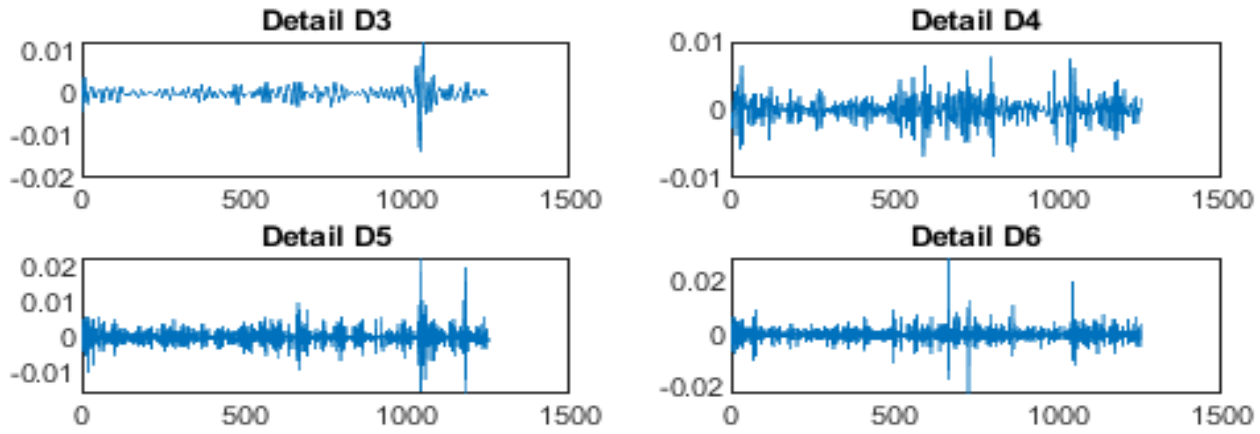

Figure 2. Wavelet decomposition of Tunindex return series at level 6.

Thew volatile behavior of the TUNINDEX is clearly shown, which confirms and The idea is to prove the existance of a fractal/multifractal scaling law in the TUNINDEx series, and/or its components. We thus proceed as mentioned previously by plotting its Hurst-H“older exponent or its spectrum of singularities. This is illustrated by Figure 3 below. 


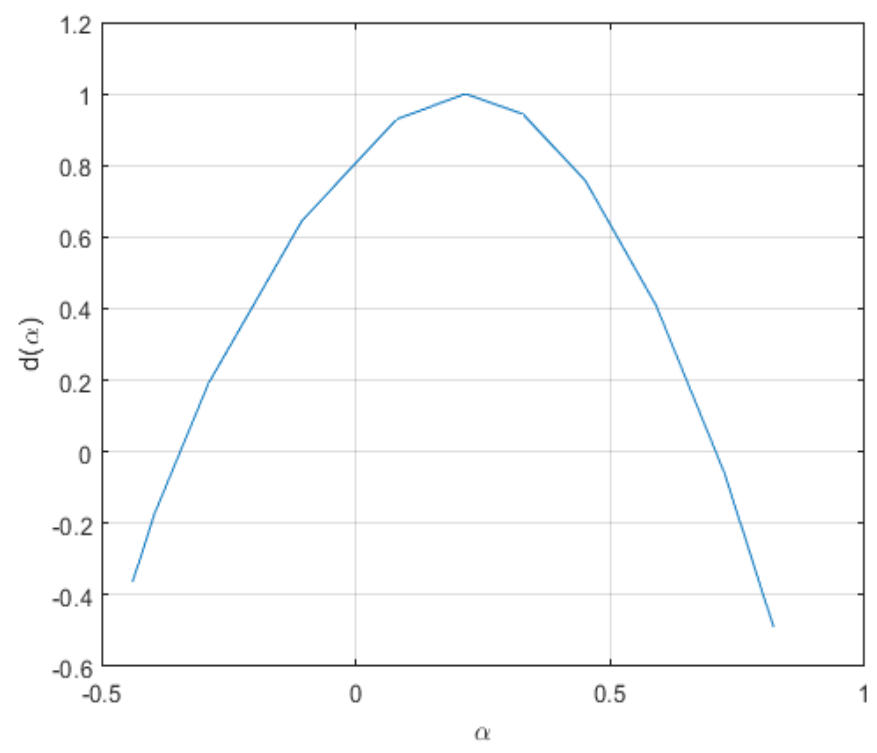

Figure 3. The multifractal spectrum of Tunindex return series.

Notice from these illustrations that although the wavelet applied is not necessarily non uniform, the market shows a concave nonlinear scaling function, or equivalently a nonlinear concave multifractal spectrum. This means that the market is multifractally volatile and it represents a point-wise scaling behavior with a point-wise changing Hurst-Holder exponent. This motivated the application of wavelet tools to explore its structure as well as its behavior by means of the CAPM.

\subsection{The classical wavelet $C A P M$ processing}

The CAPM wavelet approach estimates the systematic risk beta on a scale-by-scale wavelet decomposition of the financial time series. The wavelet variance of the market index and the co-variance between the market and the components is computed to obtain a scale-by-scale estimate of stock's beta. Table 7 represents theses estimations for all the stock components using a uniform wavelet decomposition at the levels $J=1,2,3,4,5,6$. 
Table 7: Uniform wavelet beta for each level.

\begin{tabular}{|c|c|c|c|c|c|c|}
\hline STOCKS & D1 & $\mathrm{D} 2$ & D3 & $\mathrm{D} 4$ & D5 & D6 \\
\hline $\mathrm{AB}$ & -0.0058 & 10.8224 & 8.8060 & -2.5686 & 19.6819 & -23.9260 \\
\hline ADWYA & -2.2882 & 1.6573 & 0.7644 & 0.0784 & 1.4485 & 0.2894 \\
\hline ATEC & -0.3098 & -2.4031 & -2.1237 & 0.6262 & -0.9401 & 0.1602 \\
\hline $\mathrm{AL}$ & 0.1467 & 0.4682 & 0.4818 & -0.1080 & 0.9225 & 0.4316 \\
\hline ALKM & -0.4293 & -0.3348 & -0.0901 & -3.1556 & 2.6938 & 0.1907 \\
\hline AMS & -1.1777 & 0.4045 & 0.4021 & 1.3881 & -0.6886 & -1.1341 \\
\hline ARTES & -1.6414 & 0.2592 & 0.1544 & -0.7078 & 0.4698 & 0.3621 \\
\hline ASSAD & 1.3090 & -0.4502 & 0.0548 & -4.5340 & -0.3007 & -0.0681 \\
\hline ATB & 0.3447 & 0.0946 & 0.2000 & 0.3809 & -0.3448 & 0.1018 \\
\hline ATL & -1.0770 & -0.3199 & -0.4179 & 0.3464 & -0.5067 & -0.1905 \\
\hline $\mathrm{BH}$ & 3.0369 & 0.2605 & 0.4742 & 2.9209 & 0.9372 & -1.1997 \\
\hline BHASS & 0.0656 & -0.4992 & -0.9534 & -1.1077 & -0.0282 & 1.2911 \\
\hline BHL & -2.2572 & 0.2245 & -0.2871 & 3.3041 & -0.6511 & 0.7858 \\
\hline BIAT & 0.6392 & 1.1340 & 1.0688 & 3.7823 & 0.2847 & 1.7848 \\
\hline BNA & 1.2234 & -1.1696 & -0.7282 & 0.6407 & -0.2140 & 0.5112 \\
\hline BS & 0.9569 & 0.7049 & 0.6793 & -0.5439 & 0.7257 & 0.3802 \\
\hline BT & -0.4848 & -0.4604 & -0.7623 & -0.3860 & -0.2200 & -0.8652 \\
\hline BTEI & 0.9866 & -0.3991 & -0.2950 & 0.1450 & -0.7518 & -1.0038 \\
\hline CC & -2.1892 & -0.2356 & -0.6133 & 4.2276 & -0.3530 & 0.4163 \\
\hline CELL & -0.0301 & 1.2574 & 1.2746 & 1.0497 & 1.6922 & -0.7457 \\
\hline CIL & 0.3133 & 0.1787 & 0.0899 & 0.9712 & 0.3231 & 0.5030 \\
\hline CITY & 0.6182 & 0.3557 & 0.2724 & 0.0902 & 0.6256 & -0.6090 \\
\hline CREAL & 0.0907 & -0.1389 & 0.0118 & 0.1834 & -0.4967 & 2.2908 \\
\hline $\mathrm{DH}$ & 0.4328 & 0.1575 & 0.1694 & -0.7097 & 0.0022 & 0.1035 \\
\hline ECYCL & 1.3425 & 0.1364 & 0.4144 & 0.6597 & 0.9613 & -0.5872 \\
\hline GIF & -1.8486 & -1.1806 & -1.1797 & 0.5990 & -1.5362 & -0.6681 \\
\hline HANL & -0.3796 & 0.2790 & 0.0687 & 0.8390 & 0.3842 & -0.6035 \\
\hline ICF & 0.4396 & -1.0868 & -0.7471 & -7.0126 & 1.8237 & 0.7698 \\
\hline LNDOR & 1.9304 & 2.0894 & 2.6104 & -2.1298 & 2.5789 & -1.3952 \\
\hline LSTR & 0.9055 & -0.5440 & 0.0586 & 0.3257 & -1.0613 & 1.1838 \\
\hline MGR & 1.5076 & 0.5316 & 0.8817 & 0.7304 & -0.7121 & 0.4132 \\
\hline MNP & 0.6616 & 0.4269 & 0.2874 & 0.5109 & -0.7035 & -0.6606 \\
\hline MPBS & 0.7480 & -0.4173 & -0.1181 & -0.7203 & -0.8307 & -2.4648 \\
\hline NAKL & -0.0509 & -0.1784 & -0.1213 & -0.2713 & -0.2425 & 0.5236 \\
\hline NBL & 2.3168 & -0.1255 & 0.2475 & 2.3258 & -1.3143 & 0.3416 \\
\hline OTH & -0.7798 & 0.1069 & -0.0084 & -1.2417 & -0.0557 & -0.5968 \\
\hline PLAST & 2.8624 & 2.7317 & 2.8280 & 16.0361 & 4.7460 & -0.7449 \\
\hline POULA & -1.4599 & -0.1276 & -0.2870 & 0.5253 & -1.0117 & 0.9684 \\
\hline SAH & 0.8431 & -0.0013 & 0.1688 & -3.1832 & 0.3483 & 0.3253 \\
\hline
\end{tabular}




\begin{tabular}{lcccccc}
\hline SAMAA & 1.4727 & -0.7483 & -0.4252 & -0.5312 & -1.0167 & 2.6624 \\
SCB & 0.7012 & -0.7450 & -0.4810 & -1.1657 & -0.8208 & 0.7585 \\
SERVI & -1.5955 & -0.5592 & -0.4832 & -0.1775 & -1.4936 & 0.0792 \\
SFBT & -0.1345 & 1.5196 & 1.2794 & 0.3316 & 0.1586 & 1.8079 \\
SIAM & 1.4304 & 1.0006 & 0.7132 & 1.7451 & 0.8960 & 0.5927 \\
SIMP & 0.0549 & 0.0296 & 0.0234 & -0.7653 & -0.2101 & 0.4337 \\
SIPHA & 0.0095 & -0.2565 & -0.2455 & 0.3606 & 1.5488 & 0.6600 \\
SITS & 0.4031 & -0.2085 & -0.1832 & -0.6524 & -0.0307 & 0.6124 \\
SMG & 0.7395 & 0.3061 & -0.1039 & -1.0045 & 1.0950 & -0.0382 \\
SOKNA & -1.5430 & 1.2272 & 0.8952 & 2.7420 & 1.5712 & -0.1190 \\
SOMOC & -0.2167 & 0.1739 & 0.1093 & -0.5376 & -0.1098 & -0.0857 \\
SOPAT & 3.6454 & -0.4350 & -0.0597 & -5.7672 & 0.2579 & 0.8665 \\
SOTE & 0.0351 & -3.1662 & -1.7651 & -5.1409 & -0.6427 & -0.3849 \\
SOTEM & 3.1962 & -1.5652 & -0.9122 & 1.8140 & -0.3950 & 1.6369 \\
SPDI & -0.4348 & -0.1123 & -0.1357 & -3.0575 & -0.0880 & 0.6584 \\
STAR & 0.3301 & -0.1985 & -0.0586 & 0.3669 & -0.2771 & -0.9198 \\
STB & 3.7127 & 0.7791 & 0.8423 & 1.1379 & 0.1722 & -0.1455 \\
STPAP & -1.0473 & 0.3928 & -0.0324 & 1.3691 & 0.0614 & 0.6823 \\
STPIL & 0.6868 & -1.1114 & -0.6990 & -1.2427 & -0.7562 & -1.1170 \\
STVR & -0.2567 & 0.1736 & 0.3458 & -0.4569 & 0.8693 & -0.1652 \\
TAIR & 2.5230 & -0.4463 & 0.2380 & 1.4587 & -0.6266 & 0.0747 \\
TGH & 1.0990 & 0.5406 & 0.4120 & 5.1598 & -1.9450 & 1.2579 \\
TINV & 1.9159 & -1.8687 & -1.0265 & -4.9678 & -1.3932 & -1.3193 \\
TJL & -1.2424 & 0.2993 & 0.0841 & -3.2779 & 0.9461 & -1.9180 \\
TLNET & 3.0938 & -0.4201 & -0.0828 & -1.3405 & 0.2932 & -0.0528 \\
TLS & 0.0417 & -0.1633 & -0.2220 & 0.2447 & -0.2910 & -0.0308 \\
TPR & -1.5041 & 0.1185 & -0.1120 & 0.7167 & 0.6093 & 0.5873 \\
TRE & -0.6456 & -0.0019 & -0.2737 & 0.6331 & 0.1419 & -0.9789 \\
UADH & 0.1182 & 0.5612 & 0.3026 & -2.0140 & 0.7947 & 0.3833 \\
UBCI & 1.3628 & -0.1010 & 0.1815 & -1.9463 & 0.3181 & 1.2316 \\
UIB & -0.2409 & 0.2689 & 0.1748 & 0.5254 & 0.0044 & 0.0531 \\
UMED & -0.0047 & 0.4276 & 0.3867 & -2.0484 & 0.5677 & -1.1359 \\
WIFAK & 0.2122 & -2.9050 & -2.8702 & -0.0112 & 0.0732 & 0.0265 \\
XABYT & 0.1916 & -0.0540 & -0.4878 & -2.7606 & 0.8138 & 1.4183 \\
\hline & & & & & &
\end{tabular}

Notice from Table 7 that the linear dependence between the market index and the actions becomes more illustrated relative to the previous method. Some cases have yielded zero coefficient beta by means of the previous method, however, the wavelet procedure have explained better the dependence or the contribution of these actions in the market, although being negative for some cases. (see for example AB, ATB and OTH actions), and some times returns to be perturbed at high scales. This means that to explore really the situation of this type of markets, and/or the at-the-crisis situations, more macroscopic and microscopic tools should be applied to detect the hidden facts. To explore more the dependence detected via the uniform wavelets, and to confirm the efficiency of the wavelet tool, $R^{2}$ determination coefficient relative to the estimations in 7 is provided hereafter in Table 8 . It represents precisely the determination coefficient $R^{2}$ relative to the betas of each stock component at the wavelet levels $J=1,2,3,4,5,6$. 
Table 8: Uniform wavelet $\mathrm{R}^{2}$ relative to Table 7 for each level.

\begin{tabular}{|c|c|c|c|c|c|c|}
\hline & \multicolumn{6}{|c|}{$\mathrm{R}^{2}$} \\
\hline STOCKS & D1 & D2 & D3 & $D 4$ & D5 & D6 \\
\hline $\mathrm{AB}$ & 0.0000 & 0.3652 & 0.3048 & 0.0083 & 0.8816 & 0.0227 \\
\hline ADWYA & 0.4748 & 0.2882 & 0.0519 & 0.0023 & 0.2414 & 0.0050 \\
\hline ATEC & 0.0041 & 0.1757 & 0.1242 & 0.0210 & 0.0574 & 0.0018 \\
\hline $\mathrm{AL}$ & 0.0050 & 0.0652 & 0.0453 & 0.0028 & 0.4130 & 0.0062 \\
\hline ALKM & 0.0014 & 0.0017 & 0.0001 & 0.0948 & 0.3105 & 0.0003 \\
\hline AMS & 0.1195 & 0.0099 & 0.0079 & 0.0275 & 0.0409 & 0.0297 \\
\hline ARTES & 0.3072 & 0.0129 & 0.0036 & 0.0909 & 0.7013 & 0.0210 \\
\hline ASSAD & 0.1148 & 0.0159 & 0.0002 & 0.2678 & 0.0193 & 0.0001 \\
\hline ATB & 0.0179 & 0.0022 & 0.0064 & 0.2015 & 0.0285 & 0.0008 \\
\hline ATL & 0.1516 & 0.0280 & 0.0368 & 0.0428 & 0.0802 & 0.0018 \\
\hline $\mathrm{BH}$ & 0.2617 & 0.0084 & 0.0197 & 0.6577 & 0.1336 & 0.0828 \\
\hline BHASS & 0.0003 & 0.0604 & 0.0805 & 0.0999 & 0.0001 & 0.0659 \\
\hline BHL & 0.5680 & 0.0034 & 0.0040 & 0.2823 & 0.0928 & 0.0078 \\
\hline BIAT & 0.3279 & 0.1482 & 0.1568 & 0.4355 & 0.2109 & 0.2234 \\
\hline BNA & 0.0443 & 0.1042 & 0.0300 & 0.0238 & 0.0142 & 0.0279 \\
\hline BS & 0.3263 & 0.1674 & 0.1503 & 0.0500 & 0.2404 & 0.0249 \\
\hline BT & 0.1209 & 0.0444 & 0.0108 & 0.0583 & 0.0195 & 0.1114 \\
\hline BTEI & 0.1326 & 0.0582 & 0.0217 & 0.0047 & 0.1412 & 0.0193 \\
\hline $\mathrm{CC}$ & 0.4203 & 0.0023 & 0.0146 & 0.2238 & 0.0424 & 0.0015 \\
\hline CELL & 0.0001 & 0.1467 & 0.1516 & 0.0761 & 0.5492 & 0.0086 \\
\hline CIL & 0.2614 & 0.0116 & 0.0030 & 0.2233 & 0.1200 & 0.0158 \\
\hline CITY & 0.0358 & 0.0329 & 0.0124 & 0.0009 & 0.3175 & 0.0181 \\
\hline CREAL & 0.0058 & 0.0027 & 0.0000 & 0.0691 & 0.0364 & 0.0555 \\
\hline $\mathrm{DH}$ & 0.0226 & 0.0044 & 0.0045 & 0.0356 & 0.0005 & 0.0009 \\
\hline ECYCL & 0.2264 & 0.0008 & 0.0081 & 0.0135 & 0.0571 & 0.0331 \\
\hline GIF & 0.1811 & 0.1130 & 0.0860 & 0.2950 & 0.1417 & 0.0045 \\
\hline HANL & 0.0167 & 0.0148 & 0.0007 & 0.0543 & 0.0286 & 0.0169 \\
\hline ICF & 0.4680 & 0.0638 & 0.0209 & 0.7304 & 0.1017 & 0.0070 \\
\hline LNDOR & 0.1798 & 0.1103 & 0.1624 & 0.0817 & 0.5586 & 0.0110 \\
\hline LSTR & 0.3151 & 0.0118 & 0.0002 & 0.0025 & 0.1600 & 0.0271 \\
\hline MGR & 0.1347 & 0.0378 & 0.0616 & 0.0707 & 0.0624 & 0.0039 \\
\hline MNP & 0.0613 & 0.0568 & 0.0107 & 0.1679 & 0.1202 & 0.0168 \\
\hline MPBS & 0.0524 & 0.0217 & 0.0014 & 0.0364 & 0.2750 & 0.0640 \\
\hline NAKL & 0.0054 & 0.0212 & 0.0109 & 0.0447 & 0.5672 & 0.1220 \\
\hline NBL & 0.6402 & 0.0006 & 0.0027 & 0.2965 & 0.3513 & 0.0034 \\
\hline $\mathrm{OTH}$ & 0.1204 & 0.0025 & 0.0000 & 0.2233 & 0.0067 & 0.0146 \\
\hline PLAST & 0.1879 & 0.0373 & 0.0463 & 0.3026 & 0.1380 & 0.0032 \\
\hline POULA & 0.3414 & 0.0017 & 0.0091 & 0.0435 & 0.1949 & 0.0551 \\
\hline $\mathrm{SAH}$ & 0.4946 & 0.0000 & 0.0039 & 0.4980 & 0.1155 & 0.0095 \\
\hline
\end{tabular}




\begin{tabular}{lllllll}
\hline SAMAA & 0.2631 & 0.1272 & 0.0223 & 0.0420 & 0.1863 & 0.1012 \\
SCB & 0.1995 & 0.0548 & 0.0270 & 0.0303 & 0.6222 & 0.0175 \\
SERVI & 0.3929 & 0.0120 & 0.0079 & 0.0007 & 0.5858 & 0.0001 \\
SFBT & 0.0055 & 0.0320 & 0.0272 & 0.0107 & 0.0022 & 0.3244 \\
SIAM & 0.1380 & 0.1214 & 0.0489 & 0.1089 & 0.2620 & 0.0097 \\
SIMP & 0.0002 & 0.0001 & 0.0000 & 0.0145 & 0.0069 & 0.0199 \\
SIPHA & 0.0000 & 0.0027 & 0.0025 & 0.0062 & 0.1787 & 0.0064 \\
SITS & 0.0644 & 0.0081 & 0.0045 & 0.0396 & 0.0002 & 0.0521 \\
SMG & 0.2673 & 0.0096 & 0.0011 & 0.0448 & 0.1866 & 0.0000 \\
SOKNA & 0.2224 & 0.0952 & 0.0525 & 0.5505 & 0.4317 & 0.0005 \\
SOMOC & 0.0171 & 0.0018 & 0.0009 & 0.0154 & 0.0032 & 0.0002 \\
SOPAT & 0.4077 & 0.0086 & 0.0002 & 0.5243 & 0.0165 & 0.0122 \\
SOTE & 0.0002 & 0.1000 & 0.0323 & 0.5654 & 0.0286 & 0.0038 \\
SOTEM & 0.1546 & 0.0991 & 0.0229 & 0.0806 & 0.0238 & 0.0098 \\
SPDI & 0.1063 & 0.0045 & 0.0058 & 0.6621 & 0.0084 & 0.0262 \\
STAR & 0.1069 & 0.0100 & 0.0007 & 0.0157 & 0.6342 & 0.0559 \\
STB & 0.6141 & 0.0665 & 0.0640 & 0.0589 & 0.0053 & 0.0009 \\
STPAP & 0.1600 & 0.0140 & 0.0001 & 0.0844 & 0.0005 & 0.0251 \\
STPIL & 0.0809 & 0.0637 & 0.0264 & 0.0272 & 0.0443 & 0.0163 \\
STVR & 0.0102 & 0.0046 & 0.0153 & 0.0269 & 0.1388 & 0.0006 \\
TAIR & 0.8716 & 0.0083 & 0.0027 & 0.0429 & 0.0405 & 0.0002 \\
TGH & 0.0376 & 0.0044 & 0.0027 & 0.7065 & 0.0463 & 0.0520 \\
TINV & 0.1695 & 0.1381 & 0.0400 & 0.2802 & 0.1676 & 0.0344 \\
TJL & 0.1081 & 0.0108 & 0.0007 & 0.5180 & 0.8903 & 0.0393 \\
TLNET & 0.3230 & 0.0290 & 0.0005 & 0.0976 & 0.0510 & 0.0001 \\
TLS & 0.0083 & 0.0021 & 0.0045 & 0.0017 & 0.0279 & 0.0000 \\
TPR & 0.1604 & 0.0017 & 0.0013 & 0.0450 & 0.3185 & 0.0226 \\
TRE & 0.0760 & 0.0000 & 0.0253 & 0.1583 & 0.2848 & 0.0298 \\
UADH & 0.1836 & 0.0799 & 0.0258 & 0.6651 & 0.4596 & 0.0017 \\
UBCI & 0.3116 & 0.0005 & 0.0016 & 0.0648 & 0.0089 & 0.0419 \\
UIB & 0.0170 & 0.0277 & 0.0086 & 0.0186 & 0.0000 & 0.0003 \\
UMED & 0.0000 & 0.0215 & 0.0193 & 0.1250 & 0.0633 & 0.0561 \\
WIFAK & 0.3618 & 0.0070 & 0.0087 & 0.0002 & 0.0204 & 0.0001 \\
XABYT & 0.0024 & 0.0002 & 0.0115 & 0.1243 & 0.0571 & 0.0438 \\
\hline & & & & & &
\end{tabular}

Table 8 presents some acceptable coherence with the results on the uniform wavelet beta estimation illustrated by Table 7 , although being quietly null in some cases. The market appears to be efficient at low and medium scales and the $R^{2}$ determination coefficients shows some decreasing behavior at low scales, however, it returns to be increasing at medium horizons. This yields that to invest in such a market, investors need may be to come over the microscopic and macroscopic scales of the market, and also to explore more adequately different panels to conclude about the best or good returns sectors.

In the TUNINDEX market, it appears that banking sector at low / medium horizons may be encouraging, reminiscent of some risk at high scales, which may be really explained by the instability of the market due to the political and social situations. Food sector seems to be risky, and unstable, although it contains the daily needs of consumers. This is due may be to the high increase of food prices compared to the economic situation of the society where a big percentage of the people becomes more and more poor due to unemployment situation. We notice also that transportation sector is suffering, which is the most comprehensible task due to the COVID-19 pandemic which stroked the sector of air transportation severely. The sector of eal estate, construction and/or housing presents also a bit positive evolution, which may be explained by the fact that in the crisis, the prices in such a sector may decrease, and the facilities of purchasing may be offered by the banks and/or the government to maintain some liquidity in the market. 
Recall in this context that the migrants and over-broad citizens are the major mass active in this sector.

Besides, the most important notification is the fact that although some encouraging situations appeared in some horizons, such situation did not resist in all time scales. The evolution of the market according to the time scales present already some perturbations. There are actions and sectors that start to be positively progressing which by the next present some deficiency. The findings in Tables 7 and 8 are confirmed by the next by the graphical illustrations in Figure 4 hereafter which represents the overage of wavelet excess return of the actions versus the wavelet excess return of the market at the same levels $j=1,2,3,4,5,6$.
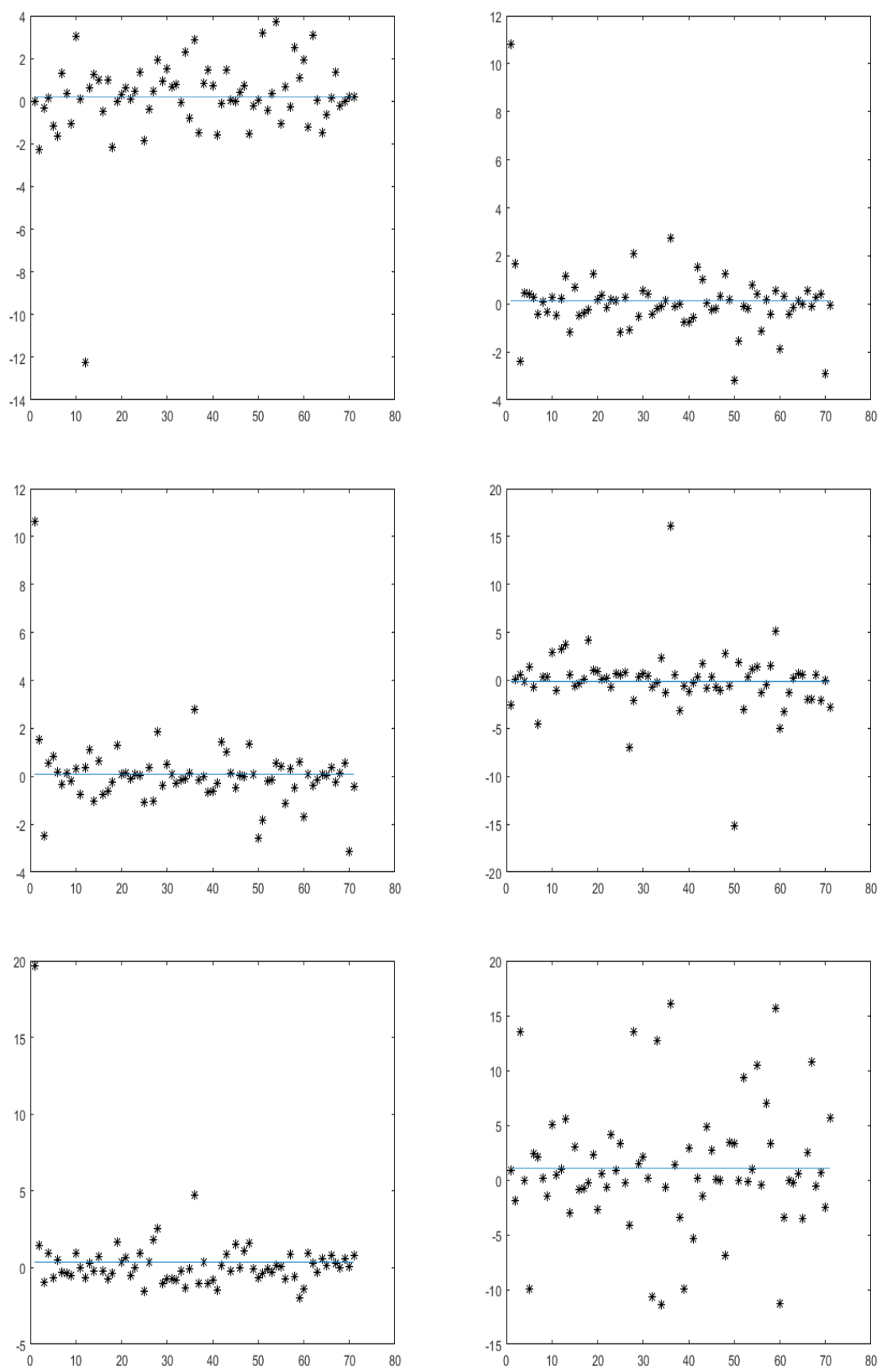

Figure 4. Uniform wavelet excess market return (horizontal axis) versus uniform wavelet excess return of the action (vertical axis) at levels $j=1,2,3,4,5,6$. 
Notice effectively from Figure 4 the linearity illustrated clearly. However, the perturbed aspect of the market is also clearly shown at the lower level, and the highest level. This may be a bad signal for investors who is/are preparing to a long time investment. This lead us to think about acting the non-uniform wavelet procedure in order to explore more the market evolution.

\subsection{The non-uniform wavelet CAPM processing}

In the present section, the purpose is to improve the WCAPm by acting the nonuniform wavelets. We pretend that such type of wavelets will lead to a best exploration of the market comprehension.

The idea empirically acts by similar way as the in the last part based on the dyadic wavelets. In the present part, we applied a non-uniform scaling law for the time intervals and the wavelets supports defined in section 3.2. By choosing suitable parameters for the subdivision $\Delta_{m}$ generated by means of a random process

$$
\Delta_{m}=\operatorname{sort}\left((b-a) * \operatorname{rand}(m, 1)+a, \text { ascend }^{\prime}\right),
$$

relative an interval $[a, b]$. In our case, the parameters are fixed to $[0, T]$, where $T$ is the size of the time series TUNINDEX, $m$ is the maximum level, which is also the number of time interval sub-segments, fixed here to $m=6$. The result of the non uniform wavelet estimation of the systematic risk beta results in 6 levels (chosen deliberately to be adequate with the previous methods). The estimations are gathered in Table 9 where for each scale, the non uniform wavelet variance of the market return and the non uniform wavelet co-variance between the market return and the stock return is computed to obtain a scale-by-scale estimate of stock's beta. 
Table 9: The non-uniform wavelet beta for each level.

\begin{tabular}{|c|c|c|c|c|c|c|}
\hline ГOCKS & $D_{1}$ & $D_{2}$ & $D_{3}$ & $D_{4}$ & $D_{5}$ & $D_{6}$ \\
\hline $\mathrm{AB}$ & -5.0353 & 7.5403 & -0.2631 & -0.0058 & 9.6819 & 0.4989 \\
\hline ADWYA & -0.3050 & 0.9530 & -0.1649 & -2.2882 & 1.4485 & 1.6849 \\
\hline ATEC & -1.7371 & -0.8598 & -2.0838 & -0.3098 & -0.9401 & -.2678 \\
\hline $\mathrm{AL}$ & 0.0825 & -0.1880 & -0.4768 & 0.1467 & 0.9225 & -.4015 \\
\hline ALKM & -0.9358 & -0.0503 & -2.0026 & -0.4293 & 2.6938 & -.9419 \\
\hline AMS & 0.5631 & -1.0126 & -1.8366 & -1.1777 & -0.6886 & 1.3822 \\
\hline ARTES & 0.0096 & -0.1066 & -0.2871 & -1.6414 & 0.4698 & 0.0569 \\
\hline ASSAD & 0.1596 & -0.3465 & 1.7453 & 1.3090 & -0.3007 & 0.7089 \\
\hline ATB & -1.2843 & 0.3100 & -0.0068 & 0.3447 & -0.3448 & 1.0966 \\
\hline ATL & 0.6763 & 0.6325 & 0.0786 & -1.0770 & -0.5067 & -.6581 \\
\hline $\mathrm{BH}$ & -0.6323 & -1.4957 & -0.1935 & 3.0369 & 0.9372 & -.7629 \\
\hline BHASS & -0.7761 & -0.7545 & -0.3824 & 0.0656 & -0.0282 & 0.1390 \\
\hline BHL & 1.3667 & 0.3190 & -1.0432 & -2.2572 & -0.6511 & -.1183 \\
\hline BIAT & -1.3302 & -0.0096 & 0.8501 & 0.6392 & 0.2847 & 1.2720 \\
\hline BNA & 0.2924 & -1.6610 & 4.1078 & 1.2234 & -0.2140 & -.0705 \\
\hline BS & -0.1458 & 0.3418 & -0.6299 & 0.9569 & 0.7257 & 1.4221 \\
\hline BT & 0.1121 & -0.3470 & 1.0324 & -0.4848 & -0.2200 & -.4777 \\
\hline BTEI & -0.6672 & -0.1344 & -0.1646 & 0.9866 & -0.7518 & -.0173 \\
\hline CC & -2.8705 & -4.2232 & 1.2398 & -2.1892 & -0.3530 & -.0183 \\
\hline CELL & 2.2966 & 1.1852 & 1.3174 & -0.0301 & 1.6922 & 0.5550 \\
\hline CIL & -0.0486 & -0.1575 & -0.0543 & 0.3133 & 0.3231 & -.6778 \\
\hline ITY & 1.9486 & -0.2252 & -0.2506 & 0.6182 & 0.6256 & -.0100 \\
\hline CREAL & 0.1003 & 0.0908 & 0.1039 & 0.0907 & -0.4967 & 1.4672 \\
\hline DH & -0.4504 & 0.5241 & 0.1825 & 0.4328 & 0.0022 & 0.5505 \\
\hline ECYCL & -0.5451 & 0.5635 & -0.8155 & 1.3425 & 0.9613 & -.8662 \\
\hline GIF & -2.7725 & -0.2349 & -1.3705 & -1.8486 & -1.5362 & 0.6733 \\
\hline HANL & 0.1466 & -0.5392 & -1.1041 & -0.3796 & 0.3842 & 0.6311 \\
\hline ICF & 0.7538 & -0.5140 & 0.5490 & 0.4396 & 1.8237 & -.6382 \\
\hline LNDOR & -0.6852 & -0.8971 & -1.5490 & 1.9304 & 2.5789 & 0.5386 \\
\hline LSTR & 4.6647 & -1.6185 & 0.0850 & 0.9055 & -1.0613 & -.5724 \\
\hline MGR & -0.2506 & -0.2998 & -0.4166 & 1.5076 & -0.7121 & 0.8805 \\
\hline MNP & 0.5342 & 0.6696 & 0.0865 & 0.6616 & -0.7035 & 0.9216 \\
\hline MPBS & 1.9565 & 0.0746 & -0.8088 & 0.7480 & -0.8307 & -.5226 \\
\hline NAKL & 0.6882 & 0.1085 & -0.0940 & -0.0509 & -0.2425 & -.1455 \\
\hline NBL & 0.1017 & 1.2616 & -0.6420 & 2.3168 & -1.3143 & -.6718 \\
\hline OTH & -0.5935 & -0.4283 & 0.1610 & -0.7798 & -0.0557 & 1.5126 \\
\hline PLAST & 4.1206 & 3.2116 & 6.1627 & 2.8624 & 4.7460 & -.6910 \\
\hline POULA & -0.3940 & 0.9049 & -1.0119 & -1.4599 & -1.0117 & 2.5275 \\
\hline SAH & 2.9358 & 0.7437 & 1.6909 & 0.8431 & 0.3483 & 0.3105 \\
\hline
\end{tabular}




\begin{tabular}{lcccccc}
\hline SAMAA & 0.6585 & -0.8032 & 1.1454 & 1.4727 & -1.0167 & -.0461 \\
SCB & 1.1502 & 1.5531 & 0.0194 & 0.7012 & -0.8208 & 0.2875 \\
SERVI & -1.7777 & -1.1372 & 0.0427 & -1.5955 & -1.4936 & -.8632 \\
SFBT & -0.2028 & -1.1407 & 2.5117 & -0.1345 & 0.1586 & -.2649 \\
SIAM & -0.7879 & -0.4308 & 0.1339 & 1.4304 & 0.8960 & 2.6744 \\
SIMP & 0.3952 & 1.3442 & 0.5205 & 0.0549 & -0.2101 & 0.0033 \\
SIPHA & 0.2307 & 1.0122 & 2.4105 & 0.0095 & 1.5488 & -.9649 \\
SITS & 0.1559 & 1.0619 & -0.3050 & 0.4031 & -0.0307 & -.2903 \\
SMG & -0.0133 & 0.8811 & -2.2874 & 0.7395 & 1.0950 & -.7470 \\
SOKNA & 1.0259 & -0.9201 & 1.3230 & -1.5430 & 1.5712 & 0.7248 \\
SOMOC & -0.9663 & 0.7099 & 0.3357 & -0.2167 & -0.1098 & 1.8653 \\
SOPAT & -1.3562 & 0.3721 & 0.8164 & 3.6454 & 0.2579 & 0.1467 \\
SOTE & -3.0307 & 0.4245 & -1.5603 & 0.0351 & -0.6427 & -.3470 \\
SOTEM & -1.5077 & 5.5979 & -0.4774 & 3.1962 & -0.3950 & -.6921 \\
SPDI & 0.1228 & 0.1178 & 0.0199 & -0.4348 & -0.0880 & 1.1054 \\
STAR & -0.8572 & -0.0639 & 1.4175 & 0.3301 & -0.2771 & -.4317 \\
STB & -2.8912 & 0.9286 & 0.0575 & 3.7127 & 0.1722 & 0.9493 \\
STPAP & 0.3642 & 0.7775 & 0.0188 & -1.0473 & 0.0614 & 1.1077 \\
STPIL & 2.0058 & -0.4005 & 0.4575 & 0.6868 & -0.7562 & 0.0698 \\
STVR & -3.0913 & 0.4294 & 0.7957 & -0.2567 & 0.8693 & 1.6345 \\
TAIR & -1.1355 & -0.4848 & 0.1436 & 2.5230 & -0.6266 & -.1926 \\
TGH & 0.5325 & -0.1040 & 1.8528 & 1.0990 & -1.9450 & 2.8173 \\
TINV & -1.8065 & -0.1180 & 0.8786 & 1.9159 & -1.3932 & -.0821 \\
TJL & 0.1178 & -0.2724 & -1.0938 & -1.2424 & 0.9461 & 0.0816 \\
TLNET & -1.7191 & -0.3174 & 0.6720 & 3.0938 & 0.2932 & -.9534 \\
TLS & -0.4655 & 1.1347 & 0.0817 & 0.0417 & -0.2910 & -.0939 \\
TPR & 1.0499 & -1.1573 & 1.0399 & -1.5041 & 0.6093 & -.4334 \\
TRE & -4.4680 & 0.4078 & -0.3849 & -0.6456 & 0.1419 & -.4406 \\
UADH & -0.1535 & -0.0047 & 0.0338 & 0.1182 & 0.7947 & -.3445 \\
UBCI & -1.5562 & -0.3520 & 0.7204 & 1.3628 & 0.3181 & 1.0367 \\
UIB & 0.6015 & 1.9169 & -0.6413 & -0.2409 & 0.0044 & -.0981 \\
UMED & -0.0237 & 2.8104 & 1.2834 & -0.0047 & 0.5677 & -.0766 \\
WIFAK & -1.0690 & 0.8824 & -0.1407 & 0.2122 & 0.0732 & 0.4194 \\
XABYT & 3.4503 & 0.1040 & 1.3244 & 0.1916 & 0.8138 & -.1719 \\
\hline & & & & & &
\end{tabular}

Notice from Table 9 that contrarily to the previous cases, the linear dependence between the market and the actions is confirmed with no zero coefficients. Besides, such dependence is sometimes strongly negative, or strongly positive even for a same action at different time horizons (which may be observed since the first action $A B$ ). Compared to the previous methods, the market seems to suffer from unstable situation according to the time factor, which is conformed also in the previous sections. This makes the authorities manly to think about the real causes behind these fragile and ambiguous situation. The main causes in our opinion are, as we said in the abstract and the introduction

- the unstable political situation in the country during this period.

- the possible corruption in the governments during this period.

- the social movements and strikes which yielded a migration of many investors.

However, although many actions in the market have shown some perturbation, the majority or the global view of the market shows that some stability may occur from time to time, but at random periods distributed randomly on the time horizons. These facts allows the investors, the analysts and also the authorities to think and to chose intelligently about the time of investment, and also the time of surveys studies conducted to conclude about the situation of the market. In other words, the non uniform method tells us that the market is not progressing uniformly as we thought previously, but, in 
contrast, short horizons sometimes, may be good moments to act even in the moment of long crises.

Now, as in the previous studies, the estimations are followed by the computation of the $R^{2}$ coefficient of determination. This is the subject of Table 10 below which shows precisely the estimations of the determination coefficient $R^{2}$ relative to the betas of each stock component estimated in Table 9 at the non uniform wavelet levels $J=1,2,3,4,5,6$.

Table 10: Non-uniform wavelet $\mathrm{R}^{2}$ relative to Table 9 for each level.

\begin{tabular}{|c|c|c|c|c|c|c|}
\hline & \multicolumn{6}{|c|}{$\mathrm{R}^{2}$} \\
\hline STOCKS & D1 & $D 2$ & D3 & $D 4$ & D5 & D6 \\
\hline$A B$ & 0.1930 & 0.3109 & 0.0790 & 0.0000 & 0.8816 & 0.4098 \\
\hline ADWYA & 0.1196 & 0.1178 & 0.0513 & 0.4748 & 0.2414 & 0.1650 \\
\hline ATEC & 0.1563 & 0.0942 & 0.2802 & 0.0041 & 0.0574 & 0.2471 \\
\hline $\mathrm{AL}$ & 0.1583 & 0.0073 & 0.0129 & 0.0050 & 0.4130 & 0.0495 \\
\hline ALKM & 0.1456 & 0.0021 & 0.6339 & 0.0014 & 0.3105 & 0.3013 \\
\hline AMS & 0.0361 & 0.1425 & 0.3991 & 0.1195 & 0.0409 & 0.0988 \\
\hline ARTES & 0.0000 & 0.0020 & 0.0505 & 0.3072 & 0.7013 & 0.0004 \\
\hline ASSAD & 0.0044 & 0.0211 & 0.4001 & 0.1148 & 0.0193 & 0.1327 \\
\hline АТВ & 0.5294 & 0.2396 & 0.0000 & 0.0179 & 0.0285 & 0.3379 \\
\hline ATL & 0.1426 & 0.1174 & 0.0034 & 0.1516 & 0.0802 & 0.0615 \\
\hline $\mathrm{BH}$ & 0.0339 & 0.3191 & 0.0027 & 0.2617 & 0.1336 & 0.6233 \\
\hline BHASS & 0.1014 & 0.2837 & 0.1241 & 0.0003 & 0.0001 & 0.0092 \\
\hline BHL & 0.2123 & 0.0779 & 0.0807 & 0.5680 & 0.0928 & 0.0003 \\
\hline BIAT & 0.4806 & 0.0000 & 0.1690 & 0.3279 & 0.2109 & 0.2847 \\
\hline BNA & 0.0069 & 0.1576 & 0.7922 & 0.0443 & 0.0142 & 0.7113 \\
\hline BS & 0.0148 & 0.0365 & 0.0651 & 0.3263 & 0.2404 & 0.3097 \\
\hline BT & 0.0062 & 0.0376 & 0.0636 & 0.1209 & 0.0195 & 0.1175 \\
\hline BTEI & 0.5943 & 0.0786 & 0.0605 & 0.1326 & 0.1412 & 0.0009 \\
\hline CC & 0.2106 & 0.4105 & 0.1756 & 0.4203 & 0.0424 & 0.0001 \\
\hline CELL & 0.2811 & 0.2861 & 0.3404 & 0.0001 & 0.5492 & 0.0209 \\
\hline CIL & 0.0009 & 0.0465 & 0.0117 & 0.2614 & 0.1200 & 0.1324 \\
\hline CITY & 0.3401 & 0.0123 & 0.0349 & 0.0358 & 0.3175 & 0.3161 \\
\hline CREAL & 0.0485 & 0.0243 & 0.0414 & 0.0058 & 0.0364 & 0.1142 \\
\hline $\mathrm{DH}$ & 0.0361 & 0.1702 & 0.0203 & 0.0226 & 0.0005 & 0.1109 \\
\hline ECYCL & 0.0431 & 0.0354 & 0.1747 & 0.2264 & 0.0571 & 0.5451 \\
\hline GIF & 0.1360 & 0.0433 & 0.2116 & 0.1811 & 0.1417 & 0.0642 \\
\hline HANL & 0.0065 & 0.1054 & 0.7015 & 0.0167 & 0.0286 & 0.4777 \\
\hline ICF & 0.0522 & 0.3983 & 0.0207 & 0.4680 & 0.1017 & 0.3747 \\
\hline LNDOR & 0.0369 & 0.0882 & 0.1227 & 0.1798 & 0.5586 & 0.0101 \\
\hline LSTR & 0.5822 & 0.2045 & 0.0013 & 0.3151 & 0.1600 & 0.0908 \\
\hline MGR & 0.0022 & 0.0332 & 0.1623 & 0.1347 & 0.0624 & 0.1970 \\
\hline MNP & 0.0266 & 0.1196 & 0.0132 & 0.0613 & 0.1202 & 0.1167 \\
\hline MPBS & 0.4882 & 0.0473 & 0.1218 & 0.0524 & 0.2750 & 0.0328 \\
\hline NAKL & 0.1829 & 0.0131 & 0.0981 & 0.0054 & 0.5672 & 0.2169 \\
\hline NBL & 0.0005 & 0.5473 & 0.0904 & 0.6402 & 0.3513 & 0.0436 \\
\hline OTH & 0.2258 & 0.1187 & 0.0234 & 0.1204 & 0.0067 & 0.4868 \\
\hline PLAST & 0.3785 & 0.4808 & 0.1906 & 0.1879 & 0.1380 & 0.0052 \\
\hline POULA & 0.2472 & 0.7316 & 0.1375 & 0.3414 & 0.1949 & 0.2025 \\
\hline SAH & 0.5347 & 0.3574 & 0.4678 & 0.4946 & 0.1155 & 0.0677 \\
\hline
\end{tabular}




\begin{tabular}{lllllll}
\hline SAMAA & 0.0887 & 0.2333 & 0.3965 & 0.2631 & 0.1863 & 0.0008 \\
SCB & 0.1400 & 0.3246 & 0.0003 & 0.1995 & 0.6222 & 0.0244 \\
SERVI & 0.1666 & 0.1787 & 0.0002 & 0.3929 & 0.5858 & 0.1001 \\
SFBT & 0.0138 & 0.1927 & 0.4251 & 0.0055 & 0.0022 & 0.5692 \\
SIAM & 0.0365 & 0.0557 & 0.0036 & 0.1380 & 0.2620 & 0.5937 \\
SIMP & 0.1228 & 0.6525 & 0.2266 & 0.0002 & 0.0069 & 0.0000 \\
SIPHA & 0.0041 & 0.3522 & 0.3231 & 0.0000 & 0.1787 & 0.8635 \\
SITS & 0.0446 & 0.8421 & 0.0181 & 0.0644 & 0.0002 & 0.0295 \\
SMG & 0.0000 & 0.1400 & 0.4179 & 0.2673 & 0.1866 & 0.2239 \\
SOKNA & 0.4516 & 0.1732 & 0.2247 & 0.2224 & 0.4317 & 0.0832 \\
SOMOC & 0.0940 & 0.2037 & 0.0201 & 0.0171 & 0.0032 & 0.2834 \\
SOPAT & 0.0419 & 0.1038 & 0.1367 & 0.4077 & 0.0165 & 0.0015 \\
SOTE & 0.6063 & 0.0342 & 0.2813 & 0.0002 & 0.0286 & 0.0261 \\
SOTEM & 0.1056 & 0.6665 & 0.1010 & 0.1546 & 0.0238 & 0.2926 \\
SPDI & 0.0005 & 0.0030 & 0.0001 & 0.1063 & 0.0084 & 0.7178 \\
STAR & 0.1925 & 0.0005 & 0.3813 & 0.1069 & 0.6342 & 0.2493 \\
STB & 0.6539 & 0.2091 & 0.0012 & 0.6141 & 0.0053 & 0.0700 \\
STPAP & 0.0125 & 0.1933 & 0.0000 & 0.1600 & 0.0005 & 0.0699 \\
STPIL & 0.6739 & 0.0359 & 0.3717 & 0.0809 & 0.0443 & 0.0028 \\
STVR & 0.5404 & 0.0668 & 0.0289 & 0.0102 & 0.1388 & 0.2230 \\
TAIR & 0.0641 & 0.0469 & 0.0071 & 0.8716 & 0.0405 & 0.0012 \\
TGH & 0.1347 & 0.0033 & 0.5790 & 0.0376 & 0.0463 & 0.0914 \\
TINV & 0.4030 & 0.0052 & 0.1109 & 0.1695 & 0.1676 & 0.0533 \\
TJL & 0.0013 & 0.0101 & 0.2020 & 0.1081 & 0.8903 & 0.0006 \\
TLNET & 0.3105 & 0.0085 & 0.0167 & 0.3230 & 0.0510 & 0.0683 \\
TLS & 0.0257 & 0.2849 & 0.0289 & 0.0083 & 0.0279 & 0.1046 \\
TPR & 0.1626 & 0.2751 & 0.2709 & 0.1604 & 0.3185 & 0.4618 \\
TRE & 0.5792 & 0.0496 & 0.0323 & 0.0760 & 0.2848 & 0.1266 \\
UADH & 0.0092 & 0.0003 & 0.2531 & 0.1836 & 0.4596 & 0.0646 \\
UBCI & 0.0483 & 0.0439 & 0.1180 & 0.3116 & 0.0089 & 0.0431 \\
UIB & 0.0967 & 0.9159 & 0.2047 & 0.0170 & 0.0000 & 0.0203 \\
UMED & 0.0072 & 0.5987 & 0.2792 & 0.0000 & 0.0633 & 0.0008 \\
WIFAK & 0.0762 & 0.2064 & 0.0131 & 0.3618 & 0.0204 & 0.0691 \\
XABYT & 0.4986 & 0.0044 & 0.4158 & 0.0024 & 0.0571 & 0.2147 \\
\hline
\end{tabular}

Table 10 shows a coherence with results on the non uniform wavelet estimation of the systematic risk beta. The market is globally efficient but with some non monotone coefficient $R^{2}$. In fact, we may notice that in the majority of cases, the determination coefficient is going to be decreasing as the time scale increases. This may lead to some corrections and improvements on the previous interpretations. Indeed, although some random deficiencies appear for some actions, globally the market is going to reach some equilibrium at long time. This equilibrium has to be well predicted. This lead us to return to the previous idea of intelligently choosing the time of investment and surveys about the market. We think that during the unstable political and social movements, it would not be good to fix at advance the time scales and act according to them. In the contrary, predictions may be done at the basis of non uniform time scales. the global or major stability due to the non uniform time and wavelet scales is shown clearly in Figure 5 hereafter which illustrates the overage of non uniform wavelet excess return of the actions against the non uniform wavelet excess return of the market at the different wavelet levels $j=1,2,3,4,5,6$.

\subsection{The sectorial CAPM}

This last section is concerned to a setorial study of the market. In which, the classification into sectors is used to try to explore best the situation of the TUNINDEX stock market via the CAPM. Tables 11, 12 and 13 show effectively that the grouping of 

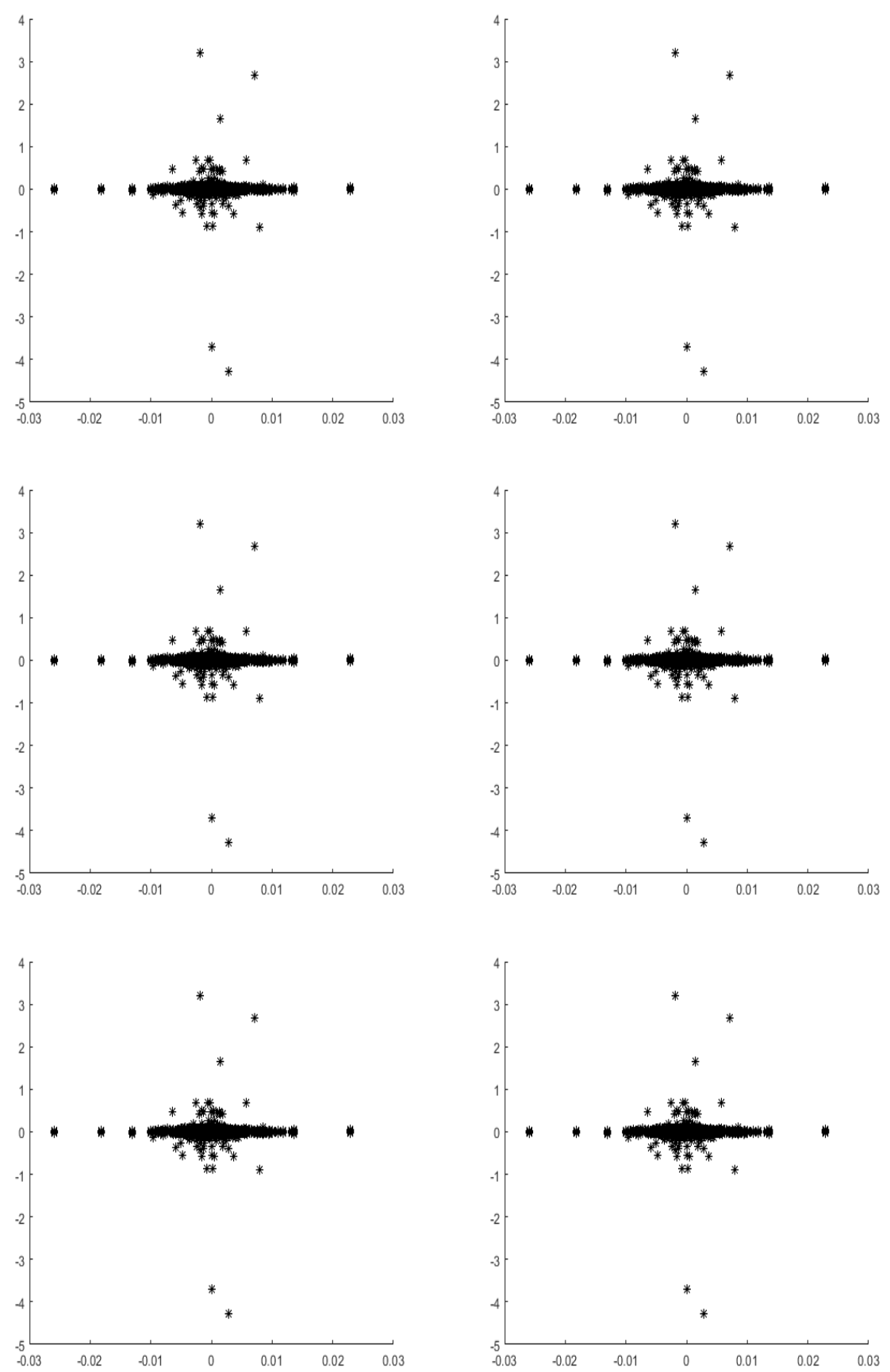

Figure 5. Non-uniform wavelet excess market return (horizontal axis) versus non-uniform wavelet excess return of the action (vertical axis) at levels $j=1,2,3,4,5,6$. 
the market components into sectors may allow us to carry a clear, out global, view of the market. Indeed, we notice that on 36 coefficients, a minimum of 29 ones are positive for the first method, 28 for the second and 32 coefficients are positive for the non uniform wavelet method. This somehow confirms that although these positivities did not resist on the same law, they explain some good hope, prospect and/or trust to the market. We notice also as in the previous sections that the sector of consumers, and finance are the most leading ones.

Table 11: The 2-scale mean beta for each sector.

\begin{tabular}{lcccccc}
\hline & \multicolumn{7}{c}{ 2-scale beta for levels $J=1$ to $J=6}$. \\
\hline Sectors & Scale 1 & Scale 2 & Scale 3 & Scale 4 & Scale 5 & Scale 6 \\
\hline Basic Materials & -1.0611 & -0.3618 & 0.1180 & -0.2719 & 0.5057 & -0.1424 \\
Capital Goods & 0.5296 & 0.2936 & 0.0244 & 0.1330 & -0.3134 & 0.2167 \\
Consumer & 0.2771 & 0.3885 & 0.8016 & -0.0636 & 0.3380 & -0.0256 \\
Energy & 2.1984 & 1.3064 & 0.3233 & -0.1591 & -0.0212 & 0.00005 \\
Financial & -0.5293 & -1.1512 & 0.4497 & -0.5797 & 0.9217 & -0.0543 \\
Healthcare & 0.7489 & 0.2145 & 0.1040 & -0.3689 & 0.8752 & 0.3228 \\
Services & -0.0540 & 0.6342 & -0.1868 & 0.2221 & 0.0821 & -0.0574 \\
Technology & 4.1210 & -1.3169 & -0.0760 & -0.4077 & -0.2706 & 0.1996 \\
Transportation & -8.7601 & 0.8458 & 0.7183 & 2.0956 & -0.4845 & 1.0164 \\
\hline
\end{tabular}

Table 12: The uniform wavelet mean Beta for each sector.

\begin{tabular}{lcccccc}
\hline & \multicolumn{7}{c}{ Uniform wavelet beta for levels $J=1$ to $J=6}$. \\
\hline Sectors & Scale 1 & Scale 2 & Scale 3 & Scale 4 & Scale 5 & Scale 6 \\
\hline Basic Materials & -0.5108 & -0.2993 & -0.2635 & -1.0733 & 0.6119 & 0.0257 \\
Capital Goods & -0.1739 & -0.1703 & -0.0875 & 0.5075 & -0.2697 & -0.0927 \\
Consumer & 0.8404 & 0.2327 & 0.3914 & 0.1848 & 0.2184 & 0.4292 \\
Energy & 0.4167 & -0.3216 & -0.1086 & -0.6754 & 0.0832 & -0.3427 \\
Financial & 0.7632 & 0.3735 & 0.3131 & -0.2386 & 1.1190 & -1.4306 \\
Healthcare & -0.7611 & 0.6095 & 0.3019 & -0.5365 & 1.1883 & -0.0622 \\
Services & -0.1230 & 0.2829 & 0.1241 & 0.3045 & -0.0979 & 0.1179 \\
Technology & 1.0624 & -1.2472 & -0.8146 & -1.0275 & -0.0984 & 0.0788 \\
Transportation & 2.5230 & -0.4463 & 0.2380 & 1.4587 & -0.6266 & 0.0747 \\
\hline
\end{tabular}

Table 13: The non-uniform wavelet mean Beta for each sector.

\begin{tabular}{lcccccc}
\hline \multicolumn{7}{c}{ Non-uniform wavelet beta for levels $J=1$ to $J=6}$. \\
\hline Sectors & Scale 1 & Scale 2 & Scale 3 & Scale 4 & Scale 5 & Scale 6 \\
\hline Basic Materials & -0.6239 & -0.6299 & 0.1742 & -0.5108 & 0.6119 & 0.3895 \\
Capital Goods & 0.1867 & 0.4635 & -0.0453 & -0.1739 & -0.2697 & 0.2186 \\
Consumer & 0.3955 & 0.1305 & 0.4990 & 0.8404 & 0.2184 & 0.2561 \\
Energy & 1.0441 & -0.2943 & -0.0096 & 0.4167 & 0.0832 & -0.1658 \\
Financial & -4.3171 & 4.1476 & 0.3692 & 0.7632 & 1.1190 & 0.3270 \\
Healthcare & -0.0327 & 1.5919 & 1.1763 & -0.7611 & 1.1883 & 0.2145 \\
Services & 0.6789 & 0.3374 & -0.0985 & -0.0617 & 0.0622 & 0.1785 \\
Technology & -1.8187 & -0.2959 & -0.7096 & 1.0624 & -0.0984 & 0.2766 \\
Transportation & -1.1355 & -0.4848 & 0.1436 & 2.5230 & -0.6266 & -0.1926 \\
\hline
\end{tabular}

\section{Conclusion}

In this paper, we proposed a wavelet multifractal procedure to estimate the systematic risk beta via the so-called CAPM. The main idea consists in testing the volatile 
behavior of the market to act next a non uniform version of wavelet analysis. Compared to the existing methods, the new process of non uniform wavelets has been proved to be more efficient and powerful in exploiting the CAPM to explore the market situation.

The theoretical methodology is applied on the case of the Tunisian TUNINDEX stock market as a representative market of the so-called Arab spring countries. The study is conducted during a critical period chosen deliberately to contain the after period of the Arab spring revolutions, and also the first COVID-19 pandemic wave appearance.

The study shows that contrarily to the existing studies, especially the old ones, the inclusion of the non uniform time scales law is adequate to understand the situation of the market during the unstable period and the crisis.

\section{Author Contributions:}

Conceptualization, M. M. Sarraj and A. Ben Mabrouk; Methodology, M. M. Sarraj and A. Ben Mabrouk; Software, M. M. Sarraj and A. Ben Mabrouk; Validation, M. M. Sarraj and A. Ben Mabrouk; Formal analysis, M. M. Sarraj and A. Ben Mabrouk; Investigation, M. M. Sarraj and A. Ben Mabrouk; Resources, M. M. Sarraj and A. Ben Mabrouk; Data curation, M. M. Sarraj and A. Ben Mabrouk; Writing-original draft preparation, M. M. Sarraj and A. Ben Mabrouk; Writing-review and editing, M. M. Sarraj and A. Ben Mabrouk; Visualization, M. M. Sarraj and A. Ben Mabrouk; Supervision, M. M. Sarraj and A. Ben Mabrouk; Project administration, M. M. Sarraj and A. Ben Mabrouk; Funding acquisition, M. M. Sarraj and A. Ben Mabrouk. All authors have read and agreed to the published version of the manuscript.

\section{Funding:}

This research received no external funding.

\section{Acknowledgments:}

The authors would like to thank the editor(s) and the anonymous reviewers for the interest given to our work and for the valuable comments which improved it.

\section{Conflicts of Interest:}

The authors declare no conflict of interest.

\section{References}

1. Black F., Jensen M. C. and M. Scholes (1972) The capital asset pricing model: Some empirical tests, in Jensen, M.C. (ed) Studies in the theory of Capital. New York: Praeger.

2. Black, F. (1972) Capital Market Equilibrium with Restricted Borrowing. Journal of Business. July, 45:3, pp. 444-55, 1972.

3. Lintner, J. (1965a) Security Prices and Maximal Gaines from Diversification. Journal of Finance, 20, pp.587-615.

4. Lintner, J. (1965b) The Valuation of Risk Assets and the Selection of Risky Investments in Stock Portfolios and Capital Budgets. The Review of Economics and Statistics, Vol. 47, No. 1., pp. 13-37.

5. Litzenberger R. H. and Ramaswamy K. (1979) The effect of personal taxes and dividends on capital asset prices: Theory and empirical evidence. Journal of Financial Economics. 7, 163-195.

6. Markowitz, H. (1952) Portfolio Selection. Journal of Finance 7, 77-91.

7. Mossin, I. (1966) Equilibrium in a Capital Asset Market. Econometrica 34, 768-783.

8. Sharpe, W. F. (1964) Capital asset prices: A theory of market equilibrium under conditions of risk. Journal of Finance 19 (3), 425-442.

9. Roll R (1977) A critique of the asset pricing theory's tests, Part I: On past and potential testability of the theory. Journal of Financial Economics. 4, 129-176.

10. Fama, E and French, (1996) The CAPM is Wanted, Dead or Alive. Journal of Finance 51, pp. 1947-1958.

11. Aydogan K (1989) Portfolio Theory, Capital Market Board of Turkey Research Report: Ankara. 
12. Banz R W (1981) The relationship between return and market value of common stock. Journal of Financial Economics 9, 3-18.

13. Basu S (1977) The relationship between earnings' yield, market value and return for NYSE common stocks-further evidence. Journal of Finance. 32, 663-681.

14. Breeden D. (1979) An Intertemporal Asset Pricing Model with Stochastic Consumption and Investment Opportunities. Journal of Financial Economics. 73, 265-296.

15. Chae J. and Yang C. (2008) Which idiosyncratic factors can explain the pricing errors from asset pricing models in the Korean stock market? Asia-Pasific Journal of Financial Studies. 37, 297-342.

16. Chan, L. K. and Lakonishok, J. (1993) Are the reports of beta's death premature? Journal of Portfolio Management, 19, 51-62.

17. Fama, E. F., (1970) Efficient capital markets: A review of theory and empirical work The journal of Finance 25 (2) (1970), 383-417.

18. Fama, E and French K, (1992) The Cross-section of Expected Stock Returns. Journal of Finance 47, pp. 427-465.

19. Fama, E and French K, (1993) Common risk factors in returns on stocks and bonds. Journal of Financial Economics 33, pp. 3-56.

20. Fama, E, and French, K (2004) The Capital Asset Pricing Model: Theory and Evidence. Journal of Economic Perspectives 18(3), pp. 25-46.

21. Fama, E, and French K, (2006) The Value Premium and the CAPM. Journal of Finance 61, pp. 2163-2185.

22. Fama E and MacBeth J. (1973) Risk, return and equilibrium: Empirical tests. Journal of Political Economy. 81, 607-636.

23. Galagedera Don U A (2007) A review of capital asset pricing models. Managerial Finance. 33, 821-832.

24. Gibbons, M. R., (1982) Multivariate tests of financial models: A new approach. Journal of Financial Economics 10 (1): 3-27.

25. Gursoy C T and Rejepova G. (2007) Test of capital asset pricing model in Turkey. Journal of Dogus University. 8, 47-58.

26. Handa P., Kothari S. P. and Wasley C. (1989) The relation between the return interval and beta: Implications for size-effect. Journal of Financial Economics, 23, 79-100.

27. Kothari, S., and Shanken, J. (1998) On defense of beta. J. Stern, and D. Chew, Jr. (Eds.), The Revolution in Corporate Finance, 3e, Blackwell Publishers Inc., pp. 52-57.

28. Cohen K, Hawawin G, Mayer S, Schwartz R. and Witcomb D. (1986) The Microstructure of Securities Markets. Prentice-Hall: Sydney.

29. Handa P., Kothari S. P., and Wasley C. (1993) Sensitivity of multivariate tests of the CAPM to the return measurement interval. Journal of Finance, 48, 1543-1551.

30. Ho Y. W., Strange R. and Piesse J. (2000) CAPM anomalies and the pricing of equity: Evidence from the Hong Kong market. Applied Economics, 2000, 32, 1629-1636.

31. Karan M B and Karadagli E (2001) Risk return and market equilibrium in Istanbul stock exchange: The test of the capital asset pricing model. Journal of Economics and Administrative Sciences. 19, 165-177.

32. Levhari D. and Levy H. (1977) The Capital Asset Pricing Model and the Investment Horizon. The Review of Economics and Statistics, 1977, vol. 59, issue 1, 92-104.

33. Merton, Robert C. (1973) An Intertermporal Capital Asset Pricing Model. Econometrica September, 41, pp. 867-87.

34. Perold, A, (2004) The Capital Asset Pricing Model. Journal of Economic Perspectives 18, pp. 3-24.

35. Marfatia, H. A. (2017a) A fresh look at integration of risks in the international stock markets: A wavelet approach. Review of Financial Economics, 34, 33-49.

36. Marfatia, H. A. (2017b) Wavelet Linkages of Global Housing Markets and macroeconomy. Available at SSRN 3169424.

37. Kishor, N. K., \& Marfatia, H. A. (2013) The time-varying response of foreign stock markets to US monetary policy surprises: Evidence from the Federal funds futures market. Journal of International Financial Markets, Institutions and Money, 24, 1-24.

38. Balalaa, M. S., Ben Mabrouk, A. and Abdessalem, H. (2021) A wavelet-based method for the impact of social media on the economic situation: The Saudi Arabia 2030-vision case. Mathematics 2021, 9(10), 1117; https:/ / doi.org/10.3390/math9101117. 
39. Ben Mabrouk, A., (2020) Wavelet-Based Systematic Risk Estimation: Application on GCC Stock Markets: The Saudi Arabia Case. Quantitative Finance and Economics, 2020, 4(4): 542-595 doi: 10.3934/QFE.2020026.

40. Ben Mabrouk, A, Kortass H and Ben Ammou S (2008) Wavelet Estimators for Long Memory in Stock Markets. Interna. J. of Theoretical and Applied Finance 12(3) (2009), 297-317.

41. Ben Mabrouk A, Kahloul I and Hallara S.-E (2010) Wavelet-Based Prediction for Governance, Diversification and Value Creation Variables. International Research Journal of Finance and Economics, 60 (2010), 15-28.

42. Ben Mabrouk A, Ben Abdallah N and Hamrita M E (2011) A wavelet method coupled with quasi self similar stochastic processes for time series approximation. Interna. J. Wavelets, Multiresolution and Information Processing, 9(5) (2011), 685-711.

43. Ben Mabrouk A and Zaafrane, O (2013) Wavelet Fuzzy Hybrid Model For Physico Financial Signals. Journal of Applied Statistics, 40(7) (2013), 1453-1463.

44. Percival D B and Walden A T (2000) Wavelet methods for time series analysis, Camridge University Press, NY.

45. Selcuk F (2005) Wavelets: A new analysis method (in Turkish). Bilkent Journal. 3, 12-14.

46. Sharpe, W. F. (1970a) Computer-Assisted Economics. Journal of Financial and Quantitative Analysis, 1970, 353-366.

47. Sharpe, W. F. (1970b) Stock market price behavior. A discussion Journal of Finance 25 (2) (1970), 418-420.

48. Sharpe, W. F. (1970c) Portfolio theory and capital markets. McGraw-Hill College

49. Brennan M. J. (1973) Taxes, market valuation and corporate financial policy. National tax journal ...

50. Lévy, H (1978) Equilibrium in an imperfect market: a constraint on the number of securities in the portfolio. American economic review, September 1978.

51. Vasichek, A. A. et McQuown, J. A. (1972) Le modèle de marché efficace. Analyse financière, 15, 1973, traduit de "The effecient market model". Financial Analyst Journal, septembreoctobre.

52. Desmoulins-Lebeault, F. (2003) Distribution of Returns and the CAPM Empirical Problems, Post-Print halshs-00165099, HAL.

53. Magni C.A. (2007a) Project selection and equivalent CAPM-based investment criteria. Applied Financial Economics Letters 3 (3) (2007), 165-168.

54. Magni C.A. (2007b) Project valuation and investment decisions: CAPM versus arbitrage. Applied Financial Economics Letters 3 (2), 137-140

55. Marfatia, H. A. (2014) Impact of uncertainty on high frequency response of the US stock markets to the Fed's policy surprises. The Quarterly Review of Economics and Finance, 54 (3), 382-392.

56. Marfatia, H. A. (2015) Monetary policy's time-varying impact on the US bond markets: Role of financial stress and risks. The North American Journal of Economics and Finance, 34, 103-123.

57. Marfatia, H. A. (2020) Investors' Risk Perceptions in the US and Global Stock Market Integration. Research in International Business and Finance, 101169. https:/ / doi.org/10.1016/j.ribaf.2019.1011

58. Gençay R., Whitcher B., and F. Selçuk (2003) Systematic Risk and Time Scales. Quantitative Finance 3, 108-116.

59. Fernandez V. (2006) The CAPM and value at risk at different time-scales. International Review of Financial Analysis, 15, 203-219.

60. Rhaiem R., Ben Ammou S. and Ben Mabrouk A. (2007a) Estimation of the systematic risk at different time scales: Application to French stock market. International Journal of Applied Economics and Finance 1(2) 79 - 87.

61. Rhaiem R., Ben Ammou S. and Ben Mabrouk A. (2007b) Wavelet estimation of systematic risk at different time scales, Application to French stock markets. International Journal of Applied Economics and Finance 1(2), 113-119.

62. Aktan B, Ozturk M, Rhaeim N and Ben Mabrouk A (2009) Wavelet-Based Systematic Risk Estimation An Application on Istanbul Stock Exchange. International Research Journal of Finance and Economics 23, 34-45.

63. Cifter A and Ozun A (2007) Multiscale systematic risk: An application on ISE 30, MPRA Paper 2484, University Library of Munich: Germany. 
64. Cifter A and Ozun A (2008) A signal processing model for time series analysis: The effect of international F/X markets on domestic currencies using wavelet networks. International Review of Electrical Engineering 3,...

65. Conlon T, Crane M and Ruskin H J (2008) Wavelet multiscale analysis for hedge funds: Scaling and strategies. Physica A. 387, 5197-5204.

66. DiSario R, Saroglu H, McCarthy J and Li H, (2008) Long memory in the volatility of an emerging equity market: The case of Turkey. International Markets Institutions and Money. 18, 305-312.

67. Gençay R, F. Selçuk and Whitcher B., (2002) An Introduction to Wavelets and Other Filtering Methods in Finance and Economics. Academic Press, San Diego.

68. Gençay R., Whitcher B. and Selçuk F. (2005) Multiscale systematic risk. Journal of International Money and Finance 24, 55-70.

69. In F and Kim S (2006) The hedge ratio and the empirical relationship between the stock and futures markets: A new approach using wavelet analysis. Journal of Business. 79, 799-820.

70. In F and Kim S (2007) A note on the relationship between Fama-French risk factors and innovations of ICAPM state variables. Finance Research Letters 4, 165-171.

71. In F, Kim S, Marisetty V and Faff R (2008) Analysing the performance of managed funds using the wavelet multiscaling method. Review of Quantitative Finance and Accounting. 31, 55-70.

72. Sharkasi A, Crane M, Ruskin H J and Matos J A, (2006) The reaction of stock markets to crashes and events: A comparison study between emerging and mature markets using wavelet transforms. Physica A. 368, 511-521.

73. Soltani S, (2002) On the use of the wavelet decomposition for time series prediction. Neurocomputing 48 (2002) 267-277.

74. Soltani, S, Modarres, R, and Eslamian, S. S., (2007) The use of time series modeling for the determination of rainfall climates of Iran. Int. J. Climatol. 27: 819-829.

75. Xiong X, Zhang X, Zhang W and Li C, (2005) Wavelet-based beta estimation of China stock market. Proceedings of 4th International Conference on Machine Learning and Cybernetic, Guangzhou. IEEE: 0-7803-9091-1.

76. Yamada H (2005) Wavelet-based beta estimation and Japanese industrial stock prices. Applied Economics Letters 12, 85-88.

77. Arfaoui S, Rezgui I and Ben Mabrouk A (2017) Wavelet Analysis On The Sphere, Spheroidal Wavelets, Degryuter, 2017, ISBN 978-3-11-048188-4.

78. Arfaoui S, Ben Mabrouk A and Cattani C (2021) Wavelet analysis Basic concepts and applications, CRC Taylor-Francis, Chapmann \& Hall, Boca Raton, 1st Ed., April 21, 2021.

79. Daubechies, I. (1992) Ten Lectures on Wavelets- Society for Industrial and Applied Mathematics. Philadelphia.

80. Hubbard B B (1998) The world according to wavelets: The story of a mathematical technique in the making, 2e, Ak Peters Ltd., MA.

81. Mallat S. (2008) A Wavelet Tour of Signal Processing. Academic Press, 3rd ed. Dec. 2008.

82. Pelissier M. and Studer C. (2018) Non-Uniform Wavelet Sampling for RF Analog-toInformation Conversion. IEEE Transactions on Circuits and Systems I: Regular Papers, 65(2) (2018), pp. 471-484, doi: 10.1109/TCSI.2017.2729779.

83. Dubeau F., Elmejdani S., and Ksantini R. (2004) Non-uniform Haar wavelets Applied Mathematics and Computation 159 (2004), pp. 675-693.

84. Brennan M., and Zhang Y. (2020) Capital Asset Pricing with a Stochastic Horizon. Journal of Financial and Quantitative Analysis, 55(3), 783-827. doi:10.1017/S0022109018001412

85. Friend, L., Landskroner, Y. \& Losq, E. (1976) The demand for risky assets and uncertain inflation. Journal of finance, décember 19974.

86. Ben Mabrouk A, Ben Abdallah N. and Dhifaoui Z. (2008) Wavelet decomposition and autoregressive model for time series prediction. Applied Mathematics and Computation 199 (2008), 334-340.

87. Zhang K., Gençay R., and Yazgan M. E. (2017) Application of wavelet decomposition in time-series forecasting. Economics Letters 158 (2017), 41-46.

88. Angue K., Régression floue: principes et applications en sciences de gestion. Université de Nice Antipolis, Laboratoire Gredge, Preprint, 2007.

89. Arfaoui S, Ben Mabrouk A and Cattani C (2021) Fractal analysis Basic concepts and applications, World Scientific, 1st Ed., December 2021. To appear. 
90. Azizieh C. (2002) Modélisation de Séries Financières par un Modèl Multifractal. Mémoire pour diplôme d'actuaire. Université Libre de Bruxelles.

91. Chen Y., Yang B. and Dong J., Time-series prediction using a local wavelet neural network. Neurocomputing, 69 (2006), 449-465.

92. Chou R. Y., Forecasting financial volatilities with extreme values: the conditional autoregressive Range (CARR) model. J. of money, credit, and banking, 37(3) (2005), 561-582.

93. Ch. M. Hafner, Cross-correlating wavelet coefficients with applications to high-frequency financial time series. J. of Applied Statistics, 39(6) (2012), 1363-1379.

94. Mitra A. and Mitra S., Forecasting business cycle mouvements using wavelets filtering and neural networks. Finance India, 18 (2004), 1605-1626.

95. Struzik Z. R., Wavelets methods in financial time series processing. Information system, Report 0023, November 30, 2000.

96. Walter C., Les échelles de temps sur les marchés financiers. Revue de Synthèse, 4(1) (2001), 55-69.

97. H. Wong, W.-Ch. Ip, Z. Xie and X. Lui, Modelling and forecasting by wavelets, and the application to exchange rates. J. of Applied Statistics, 30(5) (2003), 537-553. 
